\title{
Artificial Neural Network and Support Vector Regression Applied in Quantitative Structure-property Relationship Modelling of Solubility of Solid Solutes in Supercritical $\mathrm{CO}_{2}$
}

\author{
M. Moussaoui, ${ }^{a},{ }^{*}$ M. Laidi, ${ }^{a}$ S. Hanini, ${ }^{a}$ and M. Hentabli \\ a Laboratory of Biomaterials and Transport Phenomena (LBMPT), \\ University of Médéa, Médéa, Algeria \\ buniversity of Bouira, Bouira, Algeria
}

\begin{abstract}
In this study, the solubility of 145 solid solutes in supercritical $\mathrm{CO}_{2}\left(\mathrm{scCO}_{2}\right)$ was correlated using computational intelligence techniques based on Quantitative Structure-Property Relationship (QSPR) models. A database of 3637 solubility values has been collected from previously published papers. Dragon software was used to calculate molecular descriptors of 145 solid systems. The genetic algorithm (GA) was implemented to optimise the subset of the significantly contributed descriptors. The overall average absolute relative deviation MAARD of about $1.345 \%$ between experimental and calculated values by support vector regress SVR-QSPR model was obtained to predict the solubility of 145 solid solutes in supercritical $\mathrm{CO}_{2}$, which is better than that obtained using ANN-QSPR model of $2.772 \%$. The results show that the developed SVR-QSPR model is more accurate and can be used as an alternative powerful modelling tool for QSAR studies of the solubility of solid solutes in supercritical carbon dioxide $\left(\mathrm{scCO}_{2}\right)$. The accuracy of the proposed model was evaluated using statistical analysis by comparing the results with other models reported in the literature.
\end{abstract}

\section{Keywords}

Solubility, solid solutes, supercritical-fluids, computational intelligence techniques, quantitative structure-property relationship

\section{Introduction}

Supercritical carbon dioxide $\left(\mathrm{sCCO}_{2}\right)$ is generally used in separation processes applied in the food, chemistry, pharmaceutical, and other industries. The design and optimisation of extraction, fractionation, and purification processes are mainly based on the knowledge of the solubility of solid solutes in $\mathrm{sCCO}_{2} \cdot{ }^{1}$ The experimental measurement of the solubility (thermo-physical property) of such compounds in $\mathrm{sCCO}_{2}$ is laborious and costly. ${ }^{2}$ To avoid expensive and tedious experiments, and to fulfil the lack of solubility data and/or pure component property data required to estimate solubility, a need exists to develop flexible and robust predictive models to estimate the solubility of solid solutes in supercritical solvents using limited information. Literature reports three major modelling approaches have been used to model the solubility of a solid solute in $\mathrm{scCO}_{2}$ using equations of state, $^{3}$ semi empirical equations, ${ }^{2}$ and computational intelligence techniques such as artificial neural networks and support vector machine. ${ }^{4}$ The solid solute solubility in $\mathrm{scCO}_{2}$ is mostly modelled using density-based correlations, such as in ${ }^{5}$. Moreover, MLP-ANN also has been used successfully to model the solid solute solubility in $\mathrm{sCCO}_{2}$ based only on thermodynamic parameters. ${ }^{6}$ The least square support vector machine LS-SVM may be considered an alternative for classical approaches, such as semi empirical correlations to model the solid solute solubility in $\mathrm{SCCO}_{2} \cdot{ }^{7}$ The most common type of ANN model that is being used nowadays is multilayer perceptron (MLP)

* Corresponding author: Assist. Professor Mohammed Moussaoui Email:m.moussaoui@univ-bouira.dz feedforward neural network (FNN) trained by back-propagation (BP) algorithm. ${ }^{8}$ This ANN type has also been successfully used for mapping complex highly nonlinear input/ output relationships between one dependent variable and more independent variables of any systems. But there are numerous limitations, for instance, difficulty in deciding the criterion for the number of hidden neurons and layers, as well as over-fitting. ${ }^{9}$ To avoid these problems, SVM is formulated as a quadratic optimisation problem and ensures a global optimal solution. Some studies have proven the superiority of SVM over ANN. ${ }^{10}$ SVM method has gained a wide range of engineering applications in forecasting and regression analysis due to its attractive features and remarkable generalization performance. ${ }^{11}$ Therefore the present study was carried out to evaluate the predictive performance of computational intelligence techniques including MPL-FNN as the most used neural network type and SVM to foretell the solubility of 145 different solid solutes in $\mathrm{SCCO}_{2}$ based on a mixture between thermodynamic properties and molecular descriptors. The novelty of the developed model in contrast to previous models is its ability to extrapolate or interpolate the solubility of several solid solutes in $\mathrm{sCCO}_{2}$ with only one combination of the fitted parameters obtained during the training stage. In addition, the independent parameters were a mixture between thermodynamic properties and structural descriptors. Moreover, a simple and convivial graphical user interface was designed to compute the solubility without learning MATLAB software. Finally, a sensitivity analysis was computed by calculating the relative importance of each input parameter on the output. 


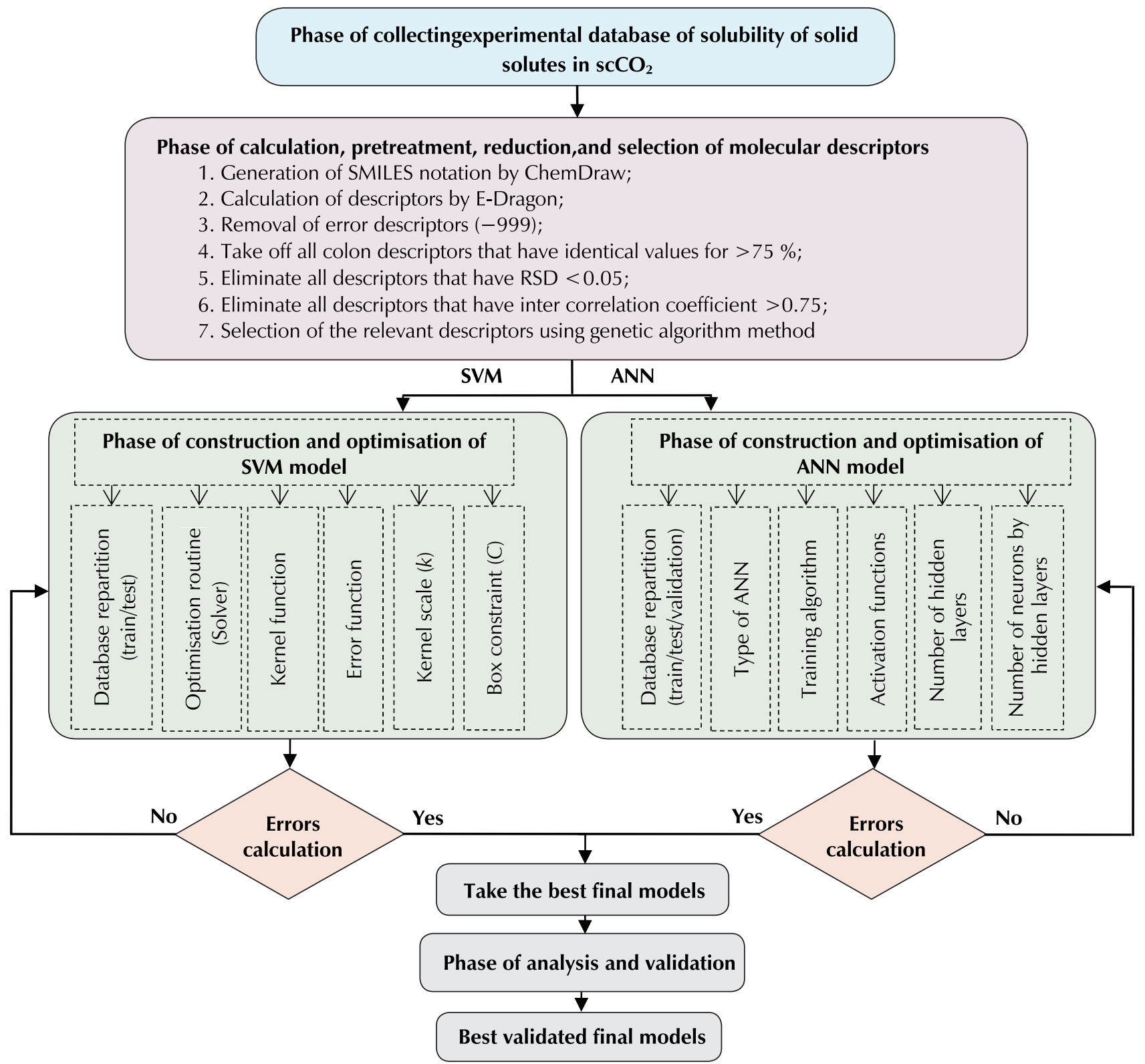

Fig. 1 - Procedure of construction and optimisation of ANN-QSPR and SVR-QSPR models

\section{Methodology}

In order to develop an ANN-QSPR or SVR-QSPR model, several steps are required, as specified in the following section (Fig. 1). ${ }^{12}$ Before sample data were given to one of the machine learning models, relevant descriptors of each system were calculated and optimised, and added to the thermodynamic parameters of each system. The data were then scaled so as to solve the problems of noise and correlated data. Next, splitting of data into two samples training and test, respectively. After settling each model architecture, its parameter optimisation was processed during the training phase. The next phase was to evaluate the performance of the optimised models using other data not used during the training stage. Lastly, statistical parameters had to be calculated to assess the accuracy of each model and validate it to be used for further prediction of solid solute solubility in $\mathrm{sCCO}_{2}$. The modelling procedure was run in MATLAB R2018a on the Windows 7 system.

\subsection{Data preparation}

Reliability and effectiveness of any model highly depends on the availability of accurate experimental data. For that, the required data for training and testing of the computational intelligence techniques were extracted from previous experimental investigations in literature.

Table 1 displays several properties of the 145 selected binary solute- $\mathrm{SCCO}_{2}$ systems counting 3637 data points of experimental solubility in $\mathrm{scCO}_{2}$, among these parameters, the name of the corresponding drugs, molecular weight, range of working temperature and pressure, experimental solubility, and references of the 145 selected systems. 
Table 1 - Sources and ranges of solubility data of solid drugs in supercritical carbon dioxide

\begin{tabular}{|c|c|c|c|c|c|c|c|c|}
\hline $\mathrm{N}^{\circ}$ & Solid solutes & $\mathrm{M} / \mathrm{g} \mathrm{mol}^{-1}$ & $\mathrm{~T} / \mathrm{K}$ & $p /$ bar & $\rho_{\mathrm{CO}_{2}} / \mathrm{kg} \mathrm{m}^{-3}$ & $-\log _{10}\left(y_{2}\right)$ & $N_{i}$ & Refs. \\
\hline 1 & $\begin{array}{l}\text { 1,5-Naphthalenediamine } \\
(1,5-N D A)\end{array}$ & 158.204 & $313.15 \sim 333.15$ & $110.00 \sim 200.00$ & $357.88 \sim 840.66$ & $4.7905 \sim 5.7212$ & 27 & 13 \\
\hline 2 & $\begin{array}{l}\text { 4,4-Diaminodiphenylmethane } \\
\text { (DADPM) }\end{array}$ & 198.269 & $313.15 \sim 333.15$ & $110.00 \sim 200.00$ & $357.88 \sim 840.66$ & $3.7940 \sim 5.0269$ & 27 & 14 \\
\hline 3 & 4-Aminoantipyrine & 203.240 & $308.20 \sim 328.20$ & $100.30 \sim 220.40$ & $338.62 \sim 879.62$ & $3.4353 \sim 4.9830$ & 21 & 15 \\
\hline 4 & Aspirin & 180.157 & $308.15 \sim 328.15$ & $120.00 \sim 250.00$ & $504.51 \sim 901.23$ & $3.4597 \sim 4.2007$ & 24 & \multirow{4}{*}{16} \\
\hline 5 & Cholesteryl acetate & 428.701 & $308.15 \sim 328.15$ & $90.00 \sim 240.00$ & $385.30 \sim 893.89$ & $2.9830 \sim 5.3615$ & 24 & \\
\hline 6 & Cholesteryl benzoate & 490.772 & $308.15 \sim 328.15$ & $120.00 \sim 270.00$ & $120.00 \sim 270.00$ & $4.2774 \sim 5.2765$ & 20 & \\
\hline 7 & Cholesteryl butyrate & 456.755 & $308.15 \sim 328.15$ & $100.00 \sim 240.00$ & $54.47 \sim 893.89$ & $3.0491 \sim 4.6497$ & 20 & \\
\hline 8 & Atorvastatin & 558.640 & $308.00 \sim 348.00$ & $121.60 \sim 354.60$ & $327.00 \sim 955.00$ & $2.8398 \sim 6.0000$ & 45 & \multirow{5}{*}{17} \\
\hline 9 & Simvastatin & 418.566 & $308.00 \sim 348.00$ & $121.60 \sim 354.60$ & $327.00 \sim 955.00$ & $3.2716 \sim 5.6990$ & 45 & \\
\hline 10 & Lovastatin & 404.550 & $308.00 \sim 348.00$ & $121.60 \sim 354.60$ & $327.00 \sim 955.00$ & $3.9431 \sim 4.9586$ & 45 & \\
\hline 11 & Rosuvastatin & 481.538 & $308.00 \sim 348.00$ & $121.60 \sim 354.60$ & $327.00 \sim 955.00$ & $3.6126 \sim 5.5229$ & 45 & \\
\hline 12 & Fluvastatin & 411.470 & $308.00 \sim 348.00$ & $121.60 \sim 354.60$ & $327.00 \sim 955.00$ & $3.2211 \sim 5.3010$ & 45 & \\
\hline 13 & Atropine & 289.369 & $308.00 \sim 348.00$ & $122.00 \sim 355.00$ & $327.00 \sim 955.00$ & $2.7773 \sim 4.2218$ & 45 & \multirow{7}{*}{18} \\
\hline 14 & Carbamazepine & 236.269 & $308.00 \sim 348.00$ & $122.00 \sim 355.00$ & $477.00 \sim 955.00$ & $4.0269 \sim 5.5229$ & 39 & \\
\hline 15 & Codeine & 299.364 & $308.00 \sim 348.00$ & $122.00 \sim 355.00$ & $327.00 \sim 955.00$ & $2.9101 \sim 4.3979$ & 45 & \\
\hline 16 & Diazepam & 284.740 & $308.00 \sim 348.00$ & $122.00 \sim 355.00$ & $327.00 \sim 955.00$ & $2.9547 \sim 3.7959$ & 45 & \\
\hline 17 & Acenaphthene & 154.212 & $308.15 \sim 348.15$ & $121.60 \sim 354.60$ & $327.00 \sim 955.00$ & $1.8540 \sim 2.8938$ & 45 & \\
\hline 18 & Fluoranthene & 202.256 & $308.15 \sim 348.15$ & $121.60 \sim 354.60$ & $327.00 \sim 955.00$ & $2.8195 \sim 3.9829$ & 45 & \\
\hline 19 & Triphenylene & 228.294 & $308.15 \sim 348.15$ & $121.60 \sim 354.60$ & $327.00 \sim 955.00$ & $4.0222 \sim 5.6989$ & 45 & \\
\hline 20 & Azelaic acid & 188.221 & $313.15 \sim 333.15$ & $100.00 \sim 300.00$ & $289.95 \sim 909.89$ & $4.9948 \sim 6.3768$ & 14 & 19 \\
\hline 21 & Benzocaine & 165.189 & $308.00 \sim 348.00$ & $122.00 \sim 355.00$ & $327.00 \sim 955.00$ & $1.9165 \sim 3.5686$ & 40 & 20 \\
\hline 22 & Benzoin & 212.248 & $308.15 \sim 328.15$ & $121.60 \sim 236.10$ & $433.42 \sim 897.99$ & $3.3872 \sim 4.3872$ & 19 & \multirow{3}{*}{21} \\
\hline 23 & Mandelic acid & 152.150 & $308.15 \sim 328.15$ & $101.00 \sim 230.60$ & $356.78 \sim 892.63$ & $2.5370 \sim 4.5686$ & 21 & \\
\hline 24 & Propyl 4-hydroxybenzoate & 180.203 & $308.15 \sim 328.15$ & $94.10 \sim 220.90$ & $361.93 \sim 885.02$ & $3.2132 \sim 4.7212$ & 21 & \\
\hline 25 & Bisacodyl & 361.400 & $308.00 \sim 348.00$ & $122.00 \sim 355.00$ & $396.00 \sim 955.00$ & $3.2343 \sim 5.0458$ & 39 & 22 \\
\hline 26 & Caffeine & 194.190 & $313.00 \sim 353.00$ & $199.00 \sim 349.00$ & $591.75 \sim 934.98$ & $2.9469 \sim 3.5482$ & 24 & 23 \\
\hline 27 & Naproxen & 230.259 & $313.10 \sim 333.10$ & $89.60 \sim 193.10$ & $394.16 \sim 840.87$ & $4.4976 \sim 5.7212$ & 18 & \multirow{4}{*}{24} \\
\hline 28 & Ketoprofen & 254.280 & $313.15 \sim 328.15$ & $90.00 \sim 250.00$ & $422.63 \sim 889.59$ & $3.7258 \sim 5.4815$ & 15 & \\
\hline 29 & Flurbiprofen & 244.261 & $303.15 \sim 323.15$ & $89.00 \sim 245.50$ & $521.40 \sim 929.10$ & $3.7059 \sim 4.7768$ & 27 & \\
\hline 30 & Ibuprofen & 206.281 & $308.15 \sim 318.15$ & $80.00 \sim 220.00$ & $290.96 \sim 890.04$ & $2.1675 \sim 4.5229$ & 29 & \\
\hline 31 & Gemfibrozil & 250.340 & $308.20 \sim 328.20$ & $100.10 \sim 220.20$ & $400.28 \sim 879.40$ & $2.3778 \sim 4.5317$ & 21 & \multirow{2}{*}{25} \\
\hline 32 & Clofibric acid & 214.645 & $308.2 \sim 328.2$ & $100.10 \sim 220.20$ & $337.35 \sim 879.40$ & $3.0675 \sim 4.4934$ & 21 & \\
\hline 33 & Irgacure $^{\circledR} 2959$ photoinitiator & 224.256 & $308.20 \sim 328.20$ & $101.00 \sim 254.00$ & $326.90 \sim 901.80$ & $3.5481 \sim 5.2840$ & 21 & 26 \\
\hline 34 & Dichlone & 227.040 & $313.00 \sim 333.00$ & $70.70 \sim 325.80$ & $160.80 \sim 905.80$ & $3.6003 \sim 5.1549$ & 23 & \multirow{2}{*}{27} \\
\hline 35 & Menadione & 172.183 & $313.00 \sim 333.00$ & $97.20 \sim 306.70$ & $273.50 \sim 306.70$ & $2.9974 \sim 3.1249$ & 18 & \\
\hline 36 & Methimazole & 114.166 & $308.00 \sim 348.00$ & $122.00-355.00$ & $327.00 \sim 955.00$ & $2.7215 \sim 4.2676$ & 40 & \multirow{3}{*}{28} \\
\hline 37 & Phenazopyridine & 213.244 & $308.00 \sim 348.00$ & $122.00-355.00$ & $327.00 \sim 955.00$ & $2.6944 \sim 4.3565$ & 45 & \\
\hline 38 & Propranolol & 259.349 & $308.00 \sim 348.00$ & $122.00 \sim 355.00$ & $327.00 \sim 955.00$ & $1.6205 \sim 3.4461$ & 45 & \\
\hline 39 & Nicotinamide & 122.127 & $313.15 \sim 373.15$ & $54.00 \sim 305.00$ & $90.15 \sim 905.74$ & $2.5031 \sim 5.0000$ & 24 & \multirow[t]{2}{*}{29} \\
\hline 40 & Nicotinic acid & 123.110 & $313.15 \sim 373.15$ & $45.00 \sim 302.00$ & $78.13 \sim 908.18$ & $4.9825 \sim 6.5086$ & 22 & \\
\hline
\end{tabular}


Table 1 - (continued)

\begin{tabular}{|c|c|c|c|c|c|c|c|c|}
\hline $\mathrm{N}^{\circ}$ & Solid solutes & $\mathrm{M} / \mathrm{g} \mathrm{mol}^{-1}$ & $T / \mathrm{K}$ & $p /$ bar & $\rho_{\mathrm{CO}_{2}} / \mathrm{kg} \mathrm{m}^{-3}$ & $-\log _{10}\left(y_{2}\right)$ & $N_{i}$ & Refs. \\
\hline 41 & Oxymetholone & 332.477 & $308.00 \sim 328.00$ & $121.00 \sim 305.00$ & $411.00 \sim 858.00$ & $3.8268 \sim 4.7959$ & 20 & \multirow{2}{*}{30} \\
\hline 42 & Cefiximetrihydrate & 507.489 & $308.00 \sim 328.00$ & $183.00 \sim 335.00$ & $634.00 \sim 875.00$ & $6.5199 \sim 6.7958$ & 18 & \\
\hline 43 & Progesterone (steroids) & 314.460 & $313.15 \sim 338.15$ & $120.00 \sim 260.00$ & $387.40 \sim 884.80$ & $2.8386 \sim 4.8539$ & 18 & 31 \\
\hline 44 & Sinapic acid & 224.212 & $313.00 \sim 333.00$ & $200.00 \sim 400.00$ & $725.00 \sim 956.00$ & $6.1524 \sim 8.1549$ & 9 & \multirow{3}{*}{32} \\
\hline 45 & Protocatechuic acid & 154.121 & $313.00 \sim 333.00$ & $200.00 \sim 400.00$ & $725.00 \sim 956.00$ & $5.9731 \sim 6.8182$ & 9 & \\
\hline 46 & Chrysin & 254.241 & $313.15 \sim 333.15$ & $200.00 \sim 400.00$ & $725.00 \sim 956.00$ & $6.9469 \sim 7.7447$ & 9 & \\
\hline 47 & Pyrocatechol & 110.112 & $308.15 \sim 363.15$ & $100.00 \sim 400.00$ & $203.00 \sim 975.00$ & $2.3388 \sim 3.9136$ & $\begin{array}{l}33 \\
32\end{array}$ & $33,34,35$ \\
\hline 48 & Phenol & 94.113 & $333.15 \sim 363.15$ & $100.00 \sim 350.00$ & $208.00 \sim 864.00$ & $1.0427 \sim 2.9431$ & 33 & 34 \\
\hline 49 & Resorcinol & 110.112 & $308.15 \sim 338.15$ & $120.00 \sim 400.00$ & $296.00 \sim 975.00$ & $3.0119 \sim 3.9586$ & 32 & 35 \\
\hline 50 & Quinine & 324.424 & $308.15 \sim 328.15$ & $80.00 \sim 240.00$ & $210.62 \sim 906.51$ & $5.0915 \sim 7.0809$ & 27 & 36 \\
\hline 51 & Salicylic acid & 138.120 & $308.15 \sim 318.15$ & $92.60 \sim 157.90$ & $463.00 \sim 824.00$ & $3.4001 \sim 4.0132$ & 20 & 37 \\
\hline 52 & Uracil & 112.080 & $313.00 \sim 333.00$ & $100.00 \sim 299.90$ & $289.40 \sim 910.00$ & $3.8861 \sim 5.6383$ & 12 & 38 \\
\hline 53 & Tributylphosphate & 266.318 & $303.00 \sim 363.00$ & $150.00 \sim 250.00$ & $372.00 \sim 923.00$ & $1,0459 \sim 1,3152$ & 24 & 39 \\
\hline 54 & $N$-phenylacetamide & 135.166 & $308.00 \sim 328.00$ & $104.40 \sim 225.00$ & $356.70 \sim 889.20$ & $3,3408 \sim 4,5331$ & 24 & 40 \\
\hline 55 & o-Phthalic acid & 166.132 & $308.00 \sim 328.00$ & $80.00 \sim 210.00$ & $206.80 \sim 875.60$ & $5,2899 \sim 5,9957$ & 15 & 41 \\
\hline 56 & 1-Aminoanthraquinone & 223.231 & $323.15 \sim 383.15$ & $125.00 \sim 250.00$ & $236.98 \sim 834.01$ & $4.4543 \sim 6.2596$ & 18 & \multirow{2}{*}{42} \\
\hline 57 & 1-Nitroanthraquinone & 253.213 & $323.15 \sim 383.15$ & $125.00 \sim 250.00$ & $236.98 \sim 834.01$ & $4.0788 \sim 4.6253$ & 18 & \\
\hline 58 & $\begin{array}{l}\text { 4-Hydroxycinnamic acid } \\
(p \text {-coumaric acid })\end{array}$ & 164.160 & $313.00 \sim 333.00$ & $150.00 \sim 500.00$ & $607.00 \sim 992.00$ & $5.5930 \sim 6.8110$ & 24 & \multirow{3}{*}{43} \\
\hline 59 & $\begin{array}{l}\text { 3,4-Dihydroxycin-namic acid } \\
\text { (caffeic acid) }\end{array}$ & 180.159 & $313.00 \sim 333.00$ & $150.00 \sim 500.00$ & $607.00 \sim 992.00$ & $7.3261 \sim 9.0969$ & 24 & \\
\hline 60 & $\begin{array}{c}\text { 4-Hydroxy-3-methoxycinnamic } \\
\text { acid (ferulic acid) }\end{array}$ & 194.186 & $313.00 \sim 333.00$ & $150.00 \sim 500.00$ & $607.00 \sim 992.00$ & $4.3633 \sim 5.4356$ & 24 & \\
\hline$\underline{61}$ & $\alpha$-Tocopherol & & $313.00 \sim 353.00$ & $199.00 \sim 349.00$ & $591.60 \sim 935.00$ & $2.4473 \sim 3.1938$ & 24 & \multirow{2}{*}{44} \\
\hline$\underline{62}$ & $\beta$-Carotene & 536.888 & $313.00 \sim 353.00$ & $200.00 \sim 350.00$ & $594.20 \sim 935.40$ & $3.9281 \sim 7.0457$ & 23 & \\
\hline 63 & 2-Methylbenzoic acid & 136.150 & $313.20 \sim 333.20$ & $110.00 \sim 246.00$ & $369.00 \sim 882.00$ & $2.2441 \sim 3.6198$ & 18 & \multirow{3}{*}{45} \\
\hline 64 & 3-Methylbenzoic acid & 136.150 & $313.20 \sim 333.20$ & $110.00 \sim 246.00$ & $369.00 \sim 882.00$ & $2.2724 \sim 3.7352$ & 18 & \\
\hline 65 & 4-Methylbenzoic acid & 136.150 & $313.20 \sim 333.20$ & $110.00 \sim 246.00$ & $369.00 \sim 882.00$ & $3.1537 \sim 4.3665$ & 18 & \\
\hline 66 & Erythromycin & 733.937 & $308.00 \sim 348.00$ & $122.00 \sim 355.00$ & $327.00 \sim 955.00$ & $3.5058 \sim 4.3665$ & 45 & 46 \\
\hline 67 & Naphthalene & 128.174 & $308.15 \sim 338.00$ & $71.90 \sim 321.50$ & $66.95 \sim 777.02$ & $0.4898 \sim 3.2881$ & 109 & 47,14 \\
\hline 68 & Amiodaronehydrochloride & 681.778 & $313.42 \sim 343.20$ & $120.00 \sim 300.00$ & $347.04 \sim 909.94$ & $2.9948 \sim 4.6003$ & 28 & 48 \\
\hline 69 & $\begin{array}{c}\text { 1-Amino-4- } \\
\text { hydroxyanthraquinone }\end{array}$ & 239.230 & $323.15 \sim 383.15$ & $125.00 \sim 250.00$ & $236.79 \sim 834.01$ & $4.6117 \sim 6.3635$ & 20 & \multirow{2}{*}{49} \\
\hline 70 & $\begin{array}{c}\text { 1-Hydroxy-4- } \\
\text { nitroanthraquinone }\end{array}$ & 269.212 & $323.15 \sim 383.15$ & $150.00 \sim 250.00$ & $303.03 \sim 834.00$ & $5.0634 \sim 6.2034$ & 15 & \\
\hline 71 & Bisphenol A & 228.291 & $308.00 \sim 328.00$ & $110.00 \sim 210.00$ & $417.06 \sim 874.40$ & $5.5212 \sim 6.9281$ & 15 & 50 \\
\hline 72 & p-Nitroaniline & 138.126 & $308.00 \sim 328.00$ & $110.00 \sim 210.00$ & $414.90 \sim 873.67$ & $4.3705 \sim 5.2055$ & 15 & 51 \\
\hline 73 & Methyl salicylate & 152.149 & $343.15 \sim 423.15$ & $90.00 \sim 310.00$ & $129.10 \sim 613.47$ & $1.1230 \sim 3.2924$ & 44 & 52 \\
\hline 74 & Juglone & 174.155 & $308.20 \sim 328.20$ & $92.00 \sim 244.00$ & $267.40 \sim 895.50$ & $2.7986 \sim 4.6989$ & 18 & 53 \\
\hline 75 & 1-Eicosanol & 298.555 & $308.20 \sim 328.20$ & $36.20 \sim 412.30$ & $71.30 \sim 976.40$ & $2.6556 \sim 4.8268$ & 24 & \multirow{2}{*}{54} \\
\hline 76 & Eicosanoicacid & 312.538 & $308.20 \sim 328.20$ & $33.70 \sim 211.20$ & $62.90 \sim 971.80$ & $2.5654 \sim 5.2006$ & 21 & \\
\hline 77 & 1-Octadecanol & 270.501 & $318.00 \sim 338.00$ & $139.90 \sim 452.80$ & $536.80 \sim 955.10$ & $1.6402 \sim 2.9830$ & 17 & \multirow{2}{*}{55} \\
\hline 78 & Stearic acid & 284.484 & $318.00 \sim 338.00$ & $145.40 \sim 467.50$ & $591.17 \sim 935.92$ & $1.8327 \sim 3.2069$ & 17 & \\
\hline 79 & Squalene & 410.730 & $313.00 \sim 333.00$ & $100.00 \sim 400.00$ & $389.00 \sim 956.00$ & $1.1124 \sim 3.3010$ & 9 & 56 \\
\hline 80 & Carbazole & 167.211 & 308.20 & $103.00 \sim 201.00$ & $706.22 \sim 865.71$ & $4.5591 \sim 4.8447$ & 5 & 57 \\
\hline
\end{tabular}


Table $1-$ (continued)

\begin{tabular}{|c|c|c|c|c|c|c|c|c|}
\hline $\mathrm{N}^{\circ}$ & Solid solutes & $\mathrm{M} / \mathrm{g} \mathrm{mol}^{-1}$ & $T / \mathrm{K}$ & $p /$ bar & $\rho_{\mathrm{CO}_{2}} / \mathrm{kg} \mathrm{m}^{-3}$ & $-\log _{10}\left(y_{2}\right)$ & $N_{i}$ & Refs. \\
\hline 81 & Anthraceneoil & 178.234 & $308.20 \sim 333.15$ & $80.00 \sim 470.00$ & $206.49 \sim 981.24$ & $3.6439 \sim 5.4828$ & $\begin{array}{c}5 \\
8 \\
23\end{array}$ & $57,58,59$ \\
\hline 82 & Ascorbylpalmitate & 414.539 & $308.10 \sim 313.10$ & $130.00 \sim 200.00$ & $720.15 \sim 865.50$ & $5.2358 \sim 5.8041$ & 8 & \multirow{5}{*}{60} \\
\hline 83 & Butyl hydroxy anisole (BHA) & 360.494 & $313.10 \sim 333.10$ & $130.00 \sim 200.00$ & $604.38 \sim 840.15$ & $1.2218 \sim 1.8416$ & 7 & \\
\hline 84 & Dodecyl gallate & 338.444 & $313.50 \sim 333.10$ & $150.00 \sim 250.00$ & $604.38 \sim 878.02$ & $4.6840 \sim 5.5086$ & 8 & \\
\hline 85 & Propyl gallate & 212.201 & $313.10 \sim 333.10$ & $150.00 \sim 250.00$ & $604.38 \sim 878.02$ & $4.1586 \sim 5.2840$ & 8 & \\
\hline 86 & Ascorbic acid & 176.124 & 313.10 & $130.00 \sim 200.00$ & $720.14 \sim 840.15$ & $4.4962 \sim 4.7328$ & 4 & \\
\hline 87 & Chrysene & 228.294 & 308.15 & $84.00 \sim 251.00$ & 539.86 901.61 & $5.0535 \sim 6.1373$ & 11 & 61 \\
\hline 88 & Triphenylene & 228.294 & $308.15 \sim 328.15$ & $85.00 \sim 252.00$ & $381.25 \sim 898.90$ & $4.3747 \sim 5.9957$ & 28 & 61 \\
\hline 89 & Lactic acid & 90.078 & $313.00 \sim 328.00$ & $58.20 \sim 197.10$ & $143.07 \sim 836.03$ & $2.7695 \sim 4.6197$ & 29 & \multirow{2}{*}{62} \\
\hline 90 & 2-Hydroxyhexanoic acid & 132.159 & $311.00 \sim 328.00$ & $74.00 \sim 198.30$ & $265.60 \sim 848.89$ & $2.5834 \sim 4.6383$ & 34 & \\
\hline 91 & Octacosane & 394.772 & 308.15 318.15 & $80.00 \sim 275.00$ & $485.60 \sim 894.80$ & 3.4089 4.9101 & 28 & \multirow{2}{*}{63} \\
\hline 92 & Triacontane & 422.826 & $308.15 \sim 318.15$ & $90.00 \sim 250.00$ & $529.90 \sim 250.00$ & $3.5210 \sim 5.2924$ & 18 & \\
\hline 93 & Hexadecanoicacid & 256.430 & $308.00 \sim 3018.00$ & $128.00 \sim 226.00$ & $639.60 \sim 884.56$ & $2.9809 \sim 3.5884$ & 10 & \multirow{3}{*}{64} \\
\hline 94 & Octadecanoicacid & 284.484 & $308.00 \sim 318.00$ & $128.00 \sim 226.00$ & $639.60 \sim 884.56$ & $3.4894 \sim 4.1308$ & 10 & \\
\hline 95 & Tetradecanoic acid & 228.376 & $308.00 \sim 318.00$ & $99.00 \sim 226.50$ & $641.91 \sim 884.92$ & $2.1278 \sim 2.9508$ & 11 & \\
\hline 96 & Artemisinin & 282.336 & $310.10 \sim 338.10$ & $100.00 \sim 270.00$ & $278.81 \sim 904.26$ & $2.5753 \sim 4.0088$ & 36 & 65 \\
\hline 97 & Ergosterol & 396.659 & $318.15 \sim 333.15$ & $120.00 \sim 240.00$ & $421.84 \sim 848.03$ & $4.5230 \sim 5.5324$ & 15 & 66 \\
\hline 98 & Cholesterol & 386.664 & $313.15 \sim 333.15$ & $100.00 \sim 250.00$ & $384.40 \sim 879.60$ & $3.8386 \sim 5.6383$ & 24 & 16,67 \\
\hline 99 & $\begin{array}{c}\text { (2,4-Dichlorophenoxyacetic } \\
\text { acid) }(2,4-D)\end{array}$ & 221.033 & $313.10 \sim 333.10$ & $104.40 \sim 207.90$ & $448.05 \sim 846.42$ & $3.9508 \sim 4.7852$ & 16 & 68 \\
\hline 100 & Methyl gallate & 184.147 & $313.00 \sim 333.00$ & $10.00 \sim 50.00$ & $295.00 \sim 992.00$ & $5.3727 \sim 7.7190$ & 27 & \multirow{2}{*}{69} \\
\hline 101 & Protocatechualdehyde & 138.122 & $313.00 \sim 333.00$ & $10.00 \sim 50.00$ & $295.00 \sim 992.00$ & $5.4270 \sim 8.4948$ & 24 & \\
\hline 102 & 1,4-Naphthoquinone & 158.156 & $308.20 \sim 328.20$ & $91.00 \sim 242.00$ & $267.80 \sim 894.93$ & $2.3071 \sim 4.3010$ & 18 & 70 \\
\hline 103 & p-Quinone (1,4-benzoquinone) & 108.096 & $308.15 \sim 318.15$ & $86.10 \sim 292.10$ & 331.97 923.84 & $1.5028 \sim 2.9730$ & 18 & \multirow{2}{*}{71} \\
\hline 104 & 9,10-Anthraquinone & 208.216 & $273.15 \sim 318.15$ & $84.10 \sim 306.30$ & $379.83 \sim 1055.76$ & $4.1308 \sim 6.0545$ & 17 & \\
\hline 105 & Syringic acid & 198.174 & $313.00 \sim 333.00$ & $100.00 \sim 500.00$ & $291.41 \sim 991.63$ & 4.8959 9.0000 & 27 & \multirow{2}{*}{72} \\
\hline 106 & Vanillic acid & 168.148 & $313.00 \sim 333.00$ & $85.00 \sim 500.00$ & 291.42 991.63 & $4.2167 \sim 6.0283$ & 28 & \\
\hline 107 & Paracetamol (acetaminophen) & 151.165 & $313.00 \sim 353.00$ & $11.00 \sim 250.00$ & $19.63 \sim 880.24$ & $5.0894 \sim 7.1427$ & 10 & 73 \\
\hline 108 & Lycopenepe & 536.885 & $323.15 \sim 353.15$ & $200.00 \sim 400.00$ & $595.40 \sim 923.80$ & $5.7277 \sim 6.1864$ & 20 & 74 \\
\hline 109 & Testosterone (steroids) & 288.431 & $308.15 \sim 328.15$ & $87.02 \sim 242.82$ & $243.85 \sim 895.47$ & $4.1543 \sim 6.4089$ & 39 & 75 \\
\hline 110 & o-Hydroxy benzoic acid & 138.122 & $273.15 \sim 328.15$ & $81.10 \sim 202.60$ & $263.59 \sim 1182.34$ & $3.2426 \sim 5.1549$ & 48 & 76 \\
\hline 111 & Acetanilide & 135.166 & $308.20 \sim 323.20$ & $90.00 \sim 400.00$ & $383.93 \sim 972.04$ & $0.3003 \sim 4.8706$ & 29 & \multirow{3}{*}{77} \\
\hline 112 & Propanamide & 73.095 & $308.20 \sim 323.20$ & $90.00 \sim 400.00$ & 284.75 972.04 & $2.2453 \sim 3.6769$ & 30 & \\
\hline 113 & Butanamide & 87.122 & $308.20 \sim 323.20$ & $90.00 \sim 400.00$ & $284.75 \sim 972.04$ & $0.9780 \sim 4.1026$ & 30 & \\
\hline 114 & Cinnamic acid & 148.161 & $308.20 \sim 328.20$ & $12.30 \sim 23.61$ & $546.67 \sim 889.50$ & $3.3716 \sim 4.4559$ & 19 & 78 \\
\hline 115 & $\begin{array}{c}\text { Geranyl butyrate } \\
\text { (10-undecenoic acid) }\end{array}$ & 184.279 & $308.00 \sim 333.00$ & $100.00 \sim 180.00$ & $291.42 \sim 845.47$ & $1.7594 \sim 3.3979$ & 18 & \multirow[t]{2}{*}{79} \\
\hline 116 & 10-Undecenoic acid & 184.279 & $308.00 \sim 333.00$ & $100.00 \sim 180.00$ & $291.42 \sim 845.47$ & $1.7594 \sim 3.3979$ & 18 & \\
\hline 117 & 2-Trifluoromethylbenzoic acid & 190.121 & $308.20 \sim 323.20$ & $93.40 \sim 226.00$ & $370.04 \sim 883.63$ & $2.0680 \sim 3.5850$ & 21 & \multirow{3}{*}{80} \\
\hline 118 & 3-Trifluoromethylbenzoic acid & 190.121 & $308.20 \sim 323.20$ & $94.10 \sim 225.40$ & $345.25 \sim 883.06$ & $1.3288 \sim 3.1487$ & 21 & \\
\hline 119 & 4-Trifluoromethylbenzoic acid & 190.121 & $308.20 \sim 323.20$ & $96.80 \sim 224.40$ & $364.09 \sim 882.48$ & $3.3410 \sim 4.5086$ & 21 & \\
\hline 120 & Cannabinol & 310.437 & $314.00 \sim 334.00$ & $130.00 \sim 202.00$ & $472.66 \sim 836.80$ & $3.3458 \sim 3.8996$ & 34 & 81 \\
\hline
\end{tabular}


Table 1 - (continued)

\begin{tabular}{|c|c|c|c|c|c|c|c|c|}
\hline $\mathrm{N}^{0}$ & Solid solutes & $\mathrm{M} / \mathrm{g} \mathrm{mol}^{-1}$ & $T / \mathrm{K}$ & $p /$ bar & $\rho_{\mathrm{CO}_{2}} / \mathrm{kg} \mathrm{m}^{-3}$ & $-\log _{10}\left(y_{2}\right)$ & $N_{i}$ & Refs \\
\hline 121 & Ethanamide (acetamide) & 59.068 & $308.20 \sim 323.20$ & $90.00 \sim 400.00$ & $284.75 \sim 972.04$ & $2.5000 \sim 3.6228$ & 30 & \multirow{2}{*}{82} \\
\hline 122 & 2-Propenamide (acrylamide) & 71.079 & $308.20 \sim 323.20$ & $90.00 \sim 400.00$ & $284.75 \sim 972.04$ & $2.7875 \sim 3.9233$ & 28 & \\
\hline 123 & Hinokitiol & 164.204 & $313.20 \sim 333.20$ & $101.40 \sim 378.30$ & 523.33 946.73 & $2.6038 \sim 23.2284$ & 30 & 83 \\
\hline 124 & lodopropynylbutylcarbamate & 281.093 & $313.15 \sim 333.15$ & $87.60 \sim 341.50$ & $417.44 \sim 930.67$ & $2.3279 \sim 2.9208$ & 27 & \multirow{2}{*}{84} \\
\hline 125 & Phenanthrene & 178.234 & 308.15 & $113.00 \sim 332.00$ & $729.62 \sim 943.89$ & $2.5952 \sim 3.1249$ & 11 & \\
\hline 126 & Levulinicacid & 116.116 & $313.00 \sim 342.40$ & $84.10 \sim 188.30$ & $268.20 \sim 824.70$ & $2.0457 \sim 3.3089$ & 34 & 85 \\
\hline 127 & $m$-Dinitrobenzene & 168.108 & $308.00 \sim 328.00$ & $95.00 \sim 145.00$ & $299.78 \sim 803.41$ & $2.2565 \sim 3.7212$ & 18 & \multirow{2}{*}{86} \\
\hline 128 & 1-Chloro-2,4-dinitrobenzene & 202.550 & $308.00 \sim 313.00$ & $95.00 \sim 145.00$ & $560.16 \sim 803.41$ & $2.2083 \sim 2.7495$ & 12 & \\
\hline 129 & Meloxicam sodium salt & 391.392 & $303.00 \sim 323.00$ & $149.00 \sim 255.00$ & $704.40 \sim 921.60$ & $4.89 .41 \sim 5.3556$ & 15 & 87 \\
\hline 130 & $\begin{array}{c}\text { N-(4-Ethoxyphenyl) } \\
\text { ethanamide }\end{array}$ & 386.665 & $308.00 \sim 328.00$ & $90.00 \sim 190.00$ & $401.55 \sim 855.74$ & $4.3685 \sim 5.0409$ & 16 & 88 \\
\hline 131 & Ketotifenfumarate (KTF) & 425.50 & $308.2 \sim 338.2$ & $120.00 \sim 300.00$ & 384.17 929.68 & $2.9679 \sim 4.6757$ & 28 & 89 \\
\hline 132 & Sertraline hydrochloride & 342.69 & $308.00 \sim 338.00$ & $120.00 \sim 300.00$ & $347.04 \sim 909.94$ & $4.0315 \sim 6.0000$ & 28 & 90 \\
\hline 133 & Aprepitant & 534.40 & $308.15 \sim 338.15$ & $120.00 \sim 300.00$ & $384.00 \sim 944.00$ & $4.1152 \sim 5.3468$ & 32 & 91 \\
\hline 134 & Coumarin-7 & 333.38 & $308.00 \sim 338.00$ & $90.00 \sim 330.00$ & $220.59 \sim 944.01$ & $4.9961 \sim 5.3819$ & 20 & 92 \\
\hline 135 & Letrozole & 285.30 & $318.20 \sim 348.20$ & $120.00 \sim 360.00$ & $318.90 \sim 922.00$ & $5.0701 \sim 5.7959$ & 20 & 93 \\
\hline 136 & Imatinibmesylate & 589.71 & $308.20 \sim 338.20$ & $120.00 \sim 270.00$ & $388.00 \sim 914.00$ & $5.3559 \sim 7.0000$ & 24 & 94 \\
\hline 137 & Esomeprazole & 345.417 & $308.20 \sim 338.20$ & $120.00 \sim 270.00$ & $382.44 \sim 912.88$ & $3.0409 \sim 4.9586$ & 24 & 95 \\
\hline 138 & Loratadine & 382.88 & $308.15 \sim 338.15$ & $120.00 \sim 270.00$ & $388.00 \sim 914.00$ & $2.8855 \sim 5.3468$ & 24 & 96 \\
\hline 139 & Lansoprazole & 369.363 & $308.20 \sim 338.20$ & $120.00 \sim 270.00$ & $382.44 \sim 912.88$ & $3.1331 \sim 4.9208$ & 27 & 97 \\
\hline 140 & Sunitinib malate & 532.56 & $308.00 \sim 338.00$ & $120.00 \sim 270.00$ & $388.00 \sim 914.00$ & $4.0675 \sim 4.8894$ & 24 & 98 \\
\hline 141 & Azathioprine & 277.263 & $308.00 \sim 338.00$ & $120.00 \sim 270.00$ & $388.00 \sim 914.00$ & $4.7375 \sim 5.5686$ & 24 & 99 \\
\hline 142 & Sorafenibtosylate & 637.03 & $308.00 \sim 338.00$ & $120.00 \sim 270.00$ & $388.00 \sim 914.00$ & $4.9006 \sim 6.1675$ & 24 & 100 \\
\hline 143 & Repaglinide & 452.595 & $308.00 \sim 338.00$ & $120.00 \sim 270.00$ & $384.00 \sim 914.00$ & $4.0214 \sim 5.5376$ & 24 & 101 \\
\hline 144 & Oxcarbazepine & 252.273 & $308.00 \sim 338.00$ & $120.00 \sim 270.00$ & $384.00 \sim 914.00$ & $4.5726 \sim 6.9586$ & 24 & 102 \\
\hline 145 & Pigment (Phthalocyanine green) & 1127.154 & $308.00 \sim 338.00$ & $120.00 \sim 270.00$ & $384.00 \sim 914.00$ & $3.9165 \sim 7.0000$ & 24 & 103 \\
\hline
\end{tabular}

\subsection{Determination of descriptors}

Quantitative Structure-Property Relationship (QSPR) models can also be used to perform property estimation since they establish quantitative correlations between diverse molecular properties and the chemical structure. ${ }^{3} \mathrm{~A}$ QSPR model consists of a mathematical relationship between the property or activity and several molecular descriptors, such as structural/topological indices or electronic/quanto-chemical properties. One of the most important steps in the construction of QSPR models is the quantification of structure information of the studied molecules, ${ }^{104}$ which are called molecular descriptors. Actually, there exist more than 11145 molecular descriptors that can be used to solve several problems in different fields, such as chemistry, biology, and other related sciences. ${ }^{105}$ In this study, 1666 molecular descriptors were calculated online by E-Dragon 1.0 software. ${ }^{106}$ The computation of these descriptors was preceded by a very interesting step, i.e., the generating of simplified molecular input-line entry system (SMILES) strings with the use of the "ChemDraw" software. After the calculation of the molecular descriptors, constant and near-constant descriptor values were removed, all missing values or at least one missing value were removed, any descriptor with a relative standard deviation $<0.001$ was removed, also descriptors with pair correlation larger or equal to $\geq 0.95$ were removed. Finally, a total set of 641 remaining descriptors was reduced as possible using stepwise regression method to select only the relevant subset of descriptors that have significant contributions to the solubility of solid solutes. After this pre-treatment, three pertinent descriptors were obtained for each system to build the ANN and SVR models ${ }^{107}$ (Table 2).

\subsection{Statistical performance evaluation criteria}

The internal predictive capability of the ANN and SVR models was evaluated by root mean square error (RMSE), average absolute relative deviation (AARD), leave-oneout (LOO) cross validation $Q^{2}{ }_{\text {LOO }}$ on the training set, and the coefficient of determination (COD). The definitions of these measures are given in Table 3, where $N$ represents 
Table 2 - The three 2D molecular descriptors used in QSPR model

\begin{tabular}{l|l|l}
\hline Descriptors & Definition & Type \\
\hline MPC2 & $\begin{array}{l}\text { molecular path count of } \\
\text { order 2 }\end{array}$ & $\begin{array}{l}\text { topological } \\
\text { descriptors }\end{array}$ \\
\hline WTPT-1 & molecular ID & $\begin{array}{l}\text { topological } \\
\text { descriptors }\end{array}$ \\
\hline AATS0i & $\begin{array}{l}\text { averaged Moreau-Broto } \\
\text { autocorrelation of lag 0 } \\
\text { weighted by ionization } \\
\text { potential }\end{array}$ & $\begin{array}{l}\text { autocorrelation } \\
\text { descriptors }\end{array}$ \\
\hline
\end{tabular}

the number of observations, $y_{2}{ }^{\exp }$ and $y_{2}{ }^{\text {cal }}$ are the desired (observed or experimental) and the predicted output values, respectively, $y_{2}^{\exp }$ is the average of experimental values of $y_{2}{ }^{\text {exp }}$.

The value of RMSE and AARD ranges from 0 to $\infty$, where the $R^{2}$ is used to determine the degree of similarity between the predict value and its observed value. In general, the best value for $R^{2}$ and $Q^{2}$ LOO is 1 , and the best value of RMSE and AARD is zero which indicates high performance of the model.

\section{Results and discussion}

\subsection{ANN-QSPR model results}

Multi-layer perceptron networks are the most widely used feedforward artificial neural networks, and are considered a powerful nonlinear black-box model for learning complex nonlinear relationships between input and output variables. The multi-layer perceptron neural networks consist of 03 connected layers: input, hidden, and output layers. The first layer receives input data and sends them to the hidden layer. After adjusting weights and biases by interconnected neurons using several non-linear transfer func- tions and different variables, the results from the hidden layer are sent to the output layer for the outputs. ${ }^{110}$

The weights of the ANN model are modified using the training algorithm until the error criterion is satisfied. In this study, the Bayesian regularisation backpropagation algorithm was used in training the ANN models. An objective function, which is the mean squared error between the outputs of the network and the target (experimental) values is used to calculate the bias and weights of the feedforward neural network. To avoid fitting problems, the number of hidden neurons is usually determined by a trial-error methodology.

In this study, this number was changed from 10 to 30 neurons using one and two hidden layers. Results have shown that ANN-QSPR with two hidden layers performs better in comparison to single layer. This procedure is repeated until the best precision is achieved for each architecture. The input parameters for the proposed model were temperature, pressure, density of $\mathrm{scCO}_{2}$, critical temperature, critical pressure, acentric factor, and the most accurate three selected 2D descriptors \{MPC2, WTPT-1, and AATSOi\}, while the output was the logarithm of the molar fraction solubility.

In the ANN model, as the inputs have different magnitudes and in order to decrease the error, a normalization must be performed on the inputs and outputs of the artificial neural network (usually between -1 and +1 ) to achieve fast convergence. The data set was randomly split into three subsets (66 \%) for the training phase, $(17 \%)$ for the testing phase, and (17\%) for the validation phase of the ANN model.

The best developed three-layer FFNN for the solubility has the structure of 9-25-20-1. This means that the ANN model has nine independent variables (thermodynamic properties and descriptors), 25 numbers of neurons in the first hidden layer, 20 numbers of neurons in the second hidden layer, and one output which is the solubility for each system. Table 4 shows the structure of the optimised ANN model. Hyperbolic tangent sigmoid (tansig) and line-

Table 3 - Definitions of performance measures ${ }^{108,109}$

\begin{tabular}{|c|c|}
\hline Measure & Formula \\
\hline $\begin{array}{l}\text { Coefficient of determination (COD) } \\
\text { Validation criteria }>0.8\end{array}$ & $R^{2}=1-\frac{\sum_{i=1}^{N}\left(y_{2}^{\exp }(i)-y_{2}^{\mathrm{cal}}(i)\right)^{2}}{\sum_{i=1}^{N}\left(y_{2}^{\exp }(i)-\widehat{y_{2}^{\exp }}\right)^{2}}$ \\
\hline Mean average absolute relative deviation (MAARD/\%) & MAARD $/ \%=\frac{100}{N} \sum_{i=1}^{N}\left|\frac{\left(y_{2}^{\exp }(i)-y_{2}^{\text {cal }}(i)\right)}{\left(y_{2}^{\exp }(i)\right)}\right|$ \\
\hline Root mean square error (RMSE) & $\operatorname{RMSE}=\left(\left(\frac{\sum_{i=1}^{N}\left(y_{2}^{\exp }(i)-y_{2}^{\text {cal }}(i)\right)^{2}}{N}\right)\right)^{1 / 2}$ \\
\hline $\begin{array}{l}\text { Leave-one-out (LOO) cross validation } Q^{2} \text { LOO } \\
\text { Validation criteria }>0.5\end{array}$ & $Q_{L O O}^{2}=1-\frac{\sum_{i=1}^{N}\left(y_{2}^{\text {exp_train }}(i)-y_{2}^{\text {cal_train }}(i)\right)^{2}}{\sum_{i=1}^{N}\left(y_{2}^{\text {exp_train }}(i)-\bar{y}_{2}^{\text {exp_train }}(i)\right)^{2}}$ \\
\hline
\end{tabular}


Table 4 - Architecture of the optimised ANN model

\begin{tabular}{|c|c|c|c|c|c|c|c|c|}
\hline \multirow{3}{*}{$\begin{array}{l}\text { ANN } \\
\text { type }\end{array}$} & \multirow{3}{*}{\begin{tabular}{|c|}
$\begin{array}{c}\text { Input } \\
\text { layer }\end{array}$ \\
$\begin{array}{l}\text { Neurons } \\
\text { number }\end{array}$
\end{tabular}} & \multicolumn{4}{|c|}{ Hidden layer } & \multirow{2}{*}{\multicolumn{2}{|c|}{ Output layer }} & \multirow{3}{*}{ Training algorithm } \\
\hline & & \multicolumn{2}{|r|}{$1^{\text {st }}$ hidden layer } & \multicolumn{2}{|r|}{$2^{\text {nd }}$ hidden layer } & & & \\
\hline & & $\begin{array}{l}\text { Neurons } \\
\text { number }\end{array}$ & Transfer function & $\begin{array}{l}\text { Neurons } \\
\text { number }\end{array}$ & Transfer function & $\begin{array}{l}\text { Neurons } \\
\text { number }\end{array}$ & $\begin{array}{l}\text { Transfer } \\
\text { function }\end{array}$ & \\
\hline MLP & 09 & 25 & $\begin{array}{c}\text { hyperbolic tangent sigmoid } \\
\text { TANSIG }\end{array}$ & 20 & $\begin{array}{c}\text { hyperbolic tangent sigmoid } \\
\text { TANSIG }\end{array}$ & 1 & purelin & $\begin{array}{c}\text { Bayesian regularisation } \\
\text { backpropagation }\end{array}$ \\
\hline
\end{tabular}

ar (purelin) functions were used as the transfer function for the hidden and output layers, respectively.

Fig. 2 displays the scatter plot of all data set of the solid solute solubility calculated using the ANN-QSPR model vs. experimental solubility (3637 experimental points). These plots were generated using the postreg function of MAT$\mathrm{LAB}$, tracing the calculated solubility as a function of experimental solubility.

In Fig. 2, the first bisector shows the exact fit between the correlated solubilities and experimental data, whereas the cross points demonstrate the real correlated solubility data by the proposed correlation vs. experimental data. In detail, the closer the points are to the solid line, the more accurate are the correlated solubility data.

The logarithmic scale of the experimental against calculated solubility is plotted in Fig. 2. On the basis of the obtained results, it can be concluded that the ANN-QSPR model was able to correlate the solubility of solids in $\mathrm{SCCO}_{2}$ with an acceptable deviation (Table 5).

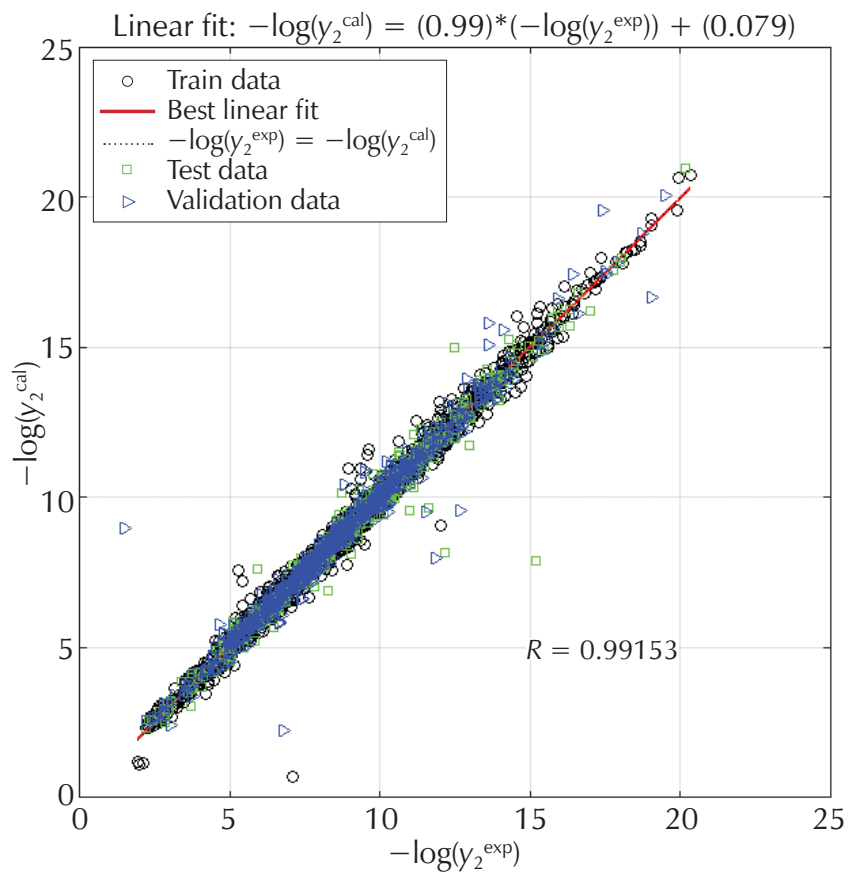

Fig. 2 - Comparison between experimental and predicted values of the solubility of 145 solutes in $\mathrm{scCO}_{2}$ using ANN
The statistical and validation values of the ANN model are listed in Table 5.

Table 5 - Statistical and validation results of the ANN-QSPR model

\begin{tabular}{l|c|c|c|c}
\hline & Training & Test & Validation & All data set \\
\hline$R^{2}$ & 0.9895 & 0.9733 & 0.9665 & 0.9830 \\
\hline mean AARD/\% & 2.637 & 2.900 & 3.189 & 2.772 \\
\hline RMSE $/ \%$ & 0.2932 & 0.4633 & 0.5241 & 0.3726 \\
\hline$Q^{2}$ LOO & 0.9895 & 0.9731 & 0.9667 & 0.9830 \\
\hline
\end{tabular}

\subsection{SVR modelling}

Support vector regress (SVR) has found many applications in different regression problems. ${ }^{111}$ This approach was firstly proposed by Vapnik. ${ }^{112}$ The quality of SVR models depends on the proper setting of SVR parameters for a given data set. The selection of these parameters (kernel width parameter $\sigma$, penalizing parameter $C$, and error-accuracy parameter $\epsilon$ ) is investigated in this section.

The same ANN inputs have been adopted to build the SVR model. The data set was randomly split into two subsets (66\%) for the training phase, (33\%) for the testing phase of the SVR model. The optimisation procedure was repeated several times in order to find the most probable global optimum of the fitness function.

In this study, radial basis function (RBF) was selected as the most common kernel function used in literature; details of the other selected parameters are summarized in Table 6.

Table 6 - Details of the proposed SVR model

\begin{tabular}{l|c}
\hline Type & Value/comment \\
\hline number of data used for training & 2425 \\
\hline number of data used for testing & 1212 \\
\hline optimisation routine (solver) & $\begin{array}{c}\text { Sequential Minimal } \\
\text { Optimisation (SMO) }\end{array}$ \\
\hline kernel function & Radial Basis Function (RBF) \\
\hline penalising parameter " $C$ " & 92 \\
\hline kernel width parameter " $\sigma$ " & 1.8 \\
\hline quantity of support vectors & 2568 \\
\hline
\end{tabular}


Table 7 - Statistical analyses for the suggested SVR model

\begin{tabular}{l|l|l|c}
\hline & Train & Test & All data set \\
\hline$R^{2}$ & 0.9952 & 0.9666 & 0.9857 \\
\hline mean AARD / \% & 0.895 & 2.247 & 1.345 \\
\hline RMSE & 0.1968 & 0.5177 & 0.3393 \\
\hline$Q^{2}$ LOO & 0.9953 & 0.9675 & 0.9859 \\
\hline
\end{tabular}

Table 7 shows a comparison between experimental and predicted values of solubility for the training, test, and all data set. Results show that the model has captured the features quite accurately with relatively high regression $\left\{R^{2}\right\}$ and low errors $\left\{\right.$ AARD and RMSE and $\left.Q^{2}{ }_{\text {LOO }}\right\}$.

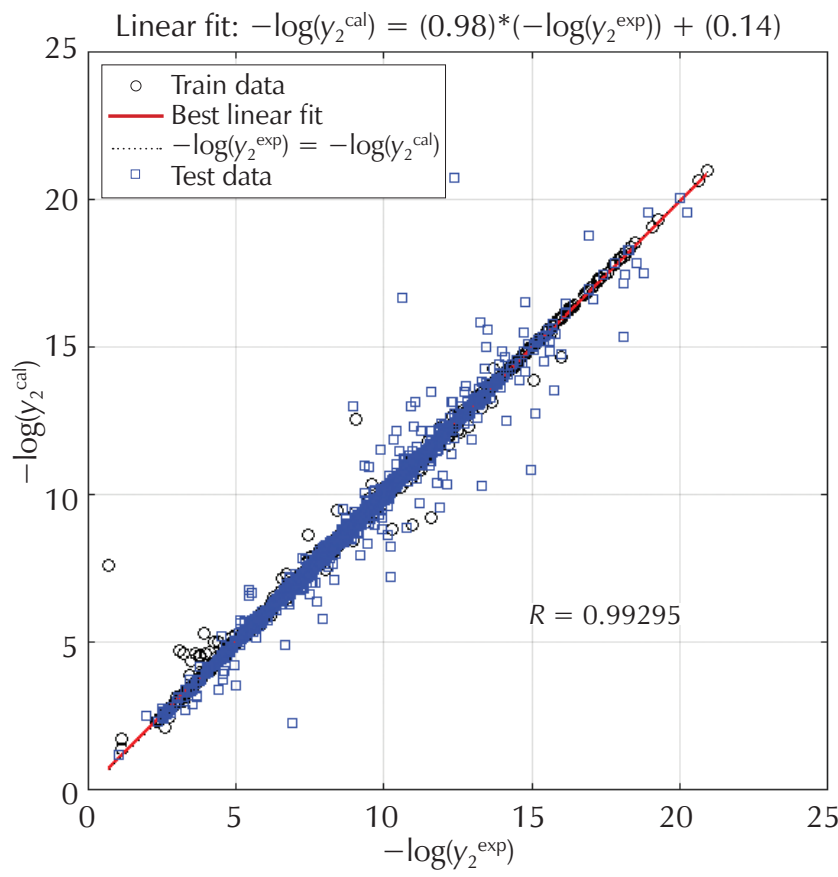

Fig. 3 - Comparison between experimental and predicted values of the solubility of 145 solutes in $\mathrm{ScCO}_{2}$ using SVR model
In Fig. 3, the capability of the model was evaluated by plotting experimental values of solubility against the predicted values by the model for all data set. The large correlation coefficient 0.9857 and a small average absolute relative deviation of 1.345 reveal the capability of the model to correlate the solubility of solid solutes in $\mathrm{sCCO}_{2}$ by knowing their physical properties.

\section{Comparison}

The comparative study between ANN-QSPR and SVRQSPR models in terms of regression and different errors using all data set was conducted (Fig. 4). The results show that the solubility data of solid solutes in $\mathrm{scCO}_{2}$ are better correlated by SVR-QSPR model than with the ANN-QSPR model. Statistical analyses show that support vector regress (SVR) predictions have an excellent agreement with the experimental data set.

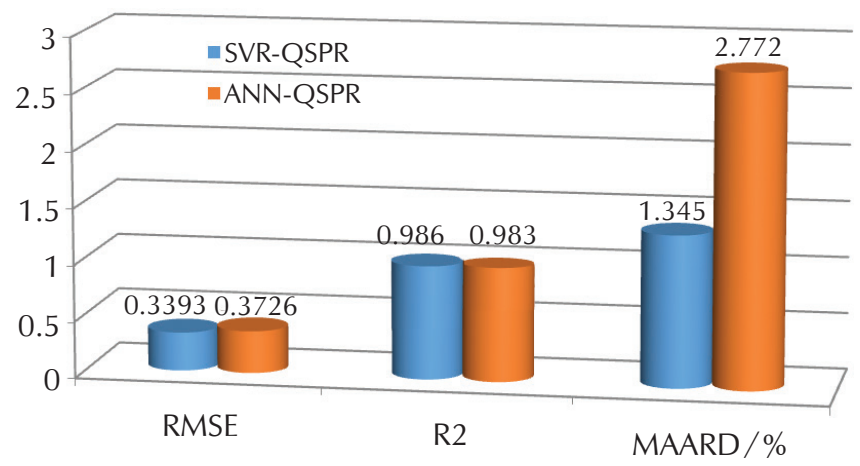

Fig. 4 - Statistical comparison between ANN and SVR models

In addition to the statistical validation of the developed models, further evaluation of the accuracy and the regression was obtained from the most relevant papers developed by other researchers (Table 8 and Fig 5). Despite numerous previously published papers in literature, the developed models in this study showed better performance in cor-

Table 8 - Comparison between the developed SVR-QSPR model in this study and other smart models reported in literature for all data set in binary solute- $\mathrm{SCCO}_{2}$ systems

\begin{tabular}{c|c|c|c|c|c|c|c|c|c}
\hline \multirow{2}{*}{ Studies } & Methods & $\begin{array}{c}\text { Compounds } \\
\text { number }\end{array}$ & Experimental data & $\begin{array}{c}\text { Model } \\
\text { inputs }\end{array}$ & $R^{2}$ & RMSE & MAARD $/ \%$ & $Q^{2}{ }_{\text {LOO }}$ & Year \\
\hline \multirow{2}{*}{ This work } & $\begin{array}{c}\text { SVR-QSPR } \\
\text { ANN-QSPR }\end{array}$ & 145 & 3637 & 9 & 0.9857 & 0.3393 & 1.3450 & 0.9859 \\
0.9830 & 0.3726 & 2.7720 & 0.9830 & 2020 \\
\hline 117 & LSSVR & 33 & 1162 & 5 & 0.9975 & - & 5.6100 & - & 2018 \\
\hline 118 & ANN & 6 & 155 & 4 & 0.91999 & - & 5.9300 & - & 2018 \\
\hline 119 & ANN & 20 & 439 & 6 & 0.9955 & - & 5.4200 & - & 2017 \\
\hline 120 & ANFIS & 29 & 795 & 6 & 0.9830 & 0.156 & 4.6617 & - & 2017 \\
\hline 121 & GWO-SVR & 18 & 1148 & 3 & 0.9936 & - & 3.20 & - & 2017 \\
\hline 122 & ANN & 8 & 198 & 5 & 0.99699 & - & 4.99 & - & 2013 \\
\hline 123 & FFNN & 21 & 795 & 6 & 0.9533 & - & 14.000 & - & 2011 \\
\hline
\end{tabular}


relating the solubility of solid solutes in $\mathrm{scCO}_{2}$ based on some relevant descriptors. The obtained models were able to correlate 145 systems (3637 data points) with lowest errors. The QSPR-SVM model was obtained with very acceptable statistical parameters, such as $R^{2}$ of 0.9857 , RMSE of 0.3393 , and MAARD of 0.9859 , as presented in Table 8. However, the global comparison in terms of the correlated systems indicated that the proposed model performed 145 systems with low errors and high collection coefficient in contrast to the other correlations, as depicted in Fig. 5.
The performance of our model (SVR-QSPR) was compared again to six density-based models previously published (Table 9).

The parameters of the selected literature models were adjusted using genetic algorithms (ga MATLAB function).

The global comparison for 145 compounds was calculated for each of the 07 studied correlations. The correlation results of the experimental data from this study are presented in terms of a comparative table of (AARD) and $R^{2}$ grouped in Table 10 and Fig 6.

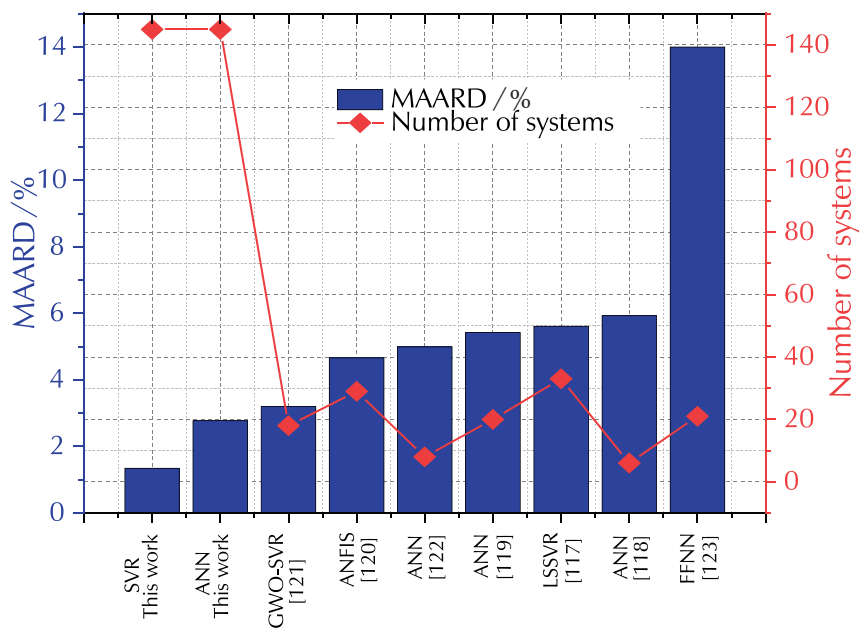

Fig. 5 - Comparison between the developed models in this study and those previously published in literature in terms of mean average absolute relative deviation

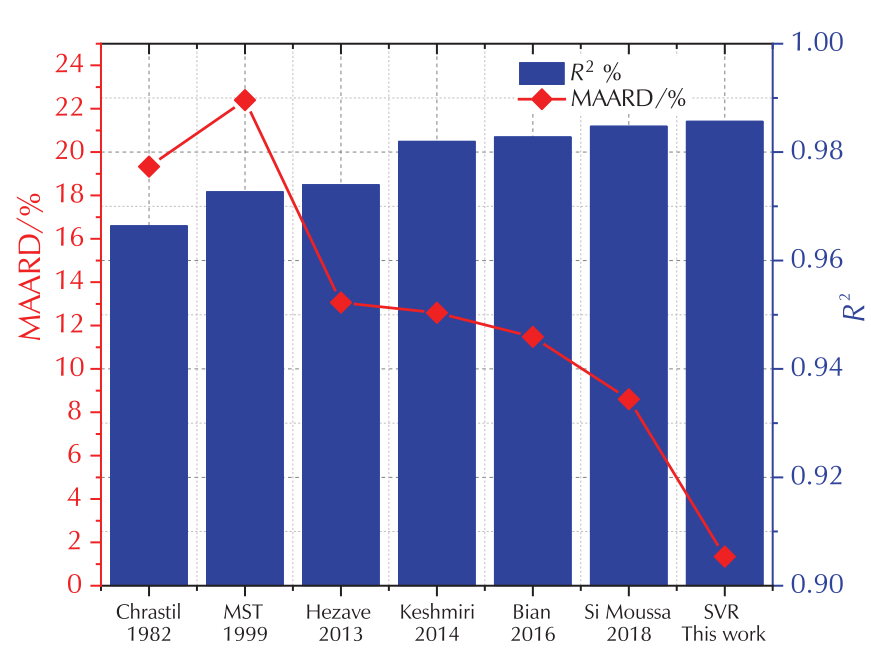

Fig. 6 - Global graphical comparison for each of the 06 density-based models and our SVR-QSPR model

Table 10 - Global comparison for each of the 06 density-based models and our SVR-QSPR model

\begin{tabular}{c|c|c|c|c|c|c|c|}
\hline Errors & $\begin{array}{c}\text { Chrastil } \\
(1982)^{113}\end{array}$ & $\begin{array}{c}\text { Mèndez-Santiago } \\
\text { and Teja (1999) }\end{array}$ & $\begin{array}{c}\text { Hezave and Lashkarbolooki } \\
(2013)^{5}\end{array}$ & $\begin{array}{c}\text { Keshmiri } \\
(2014)^{115}\end{array}$ & $\begin{array}{c}\text { Bian } \\
(2016)^{116}\end{array}$ & $\begin{array}{c}\text { Si Moussa } \\
(2018)^{2}\end{array}$ & $\begin{array}{c}\text { Our model } \\
\text { SVR-QSPR }\end{array}$ \\
\hline mean AARD/\% & 19.3312 & 22.4011 & 13.0631 & 12.5889 & 11.4792 & 8.6026 & $\mathbf{1 . 3 4 5}$ \\
\hline$R^{2}$ & 0.9664 & 0.9727 & 0.9740 & 0.9820 & 0.9828 & 0.9848 & $\mathbf{0 . 9 8 5 7}$ \\
\hline
\end{tabular}

Table 9 - Density-based models for the correlation of solid solutes in $\mathrm{scCO}_{2}$

\begin{tabular}{l|l|l}
\hline Models & Equations & Refs. \\
\hline Chrastil, 1982 & $\ln \left(y_{2}\right)=a_{0}+a_{1} \ln \left(\rho_{1}\right)$ & 113 \\
\hline Mèndez-Santiago and Teja (MST), 1999 & $\ln \left(y_{2}\right)=a_{0}+\frac{a_{1}}{T}+a_{2} P^{2}+\left(a_{3}+\frac{a_{4}}{T}\right) \ln \left(\rho_{1}\right)$ & 114 \\
\hline Hezave and Lashkarbolooki, 2013 & $\ln \left(\frac{P\left(y_{2}-d x T\right)}{P^{\text {ref }}}\right)=a+\frac{b}{T}+c\left(\rho_{1}-\rho_{\text {ref }}\right)$ & 5 \\
\hline Keshmiri et al., 2014 & $\ln \left(y_{2}\right)=a_{0}+\frac{a_{1}}{T}+a_{2} P^{2}+\left(a_{3}+\frac{a_{4}}{T}\right) \ln \left(\rho_{1}\right)$ & 115 \\
\hline Bian et al., 2016 & $\ln \left(y_{2}\right)=a_{0}+\frac{a_{1}}{T}+\frac{a_{2} \rho_{1}}{T}+\left(a_{3}+a_{4} \rho_{1}\right) \ln \left(\rho_{1}\right)$ & 116 \\
\hline Si Moussa et al., 2018 & $\ln \left(y_{2}\right)=a_{0}+a_{1} \rho_{1}+a_{2} \rho_{1}^{2}+a_{3} \rho_{1} T+a_{4} T+a_{5} T^{2}+a_{6} \ln \left(\rho_{1}\right)+\frac{a_{7}}{T}$ \\
\hline
\end{tabular}


Sharing the obtained results by SVR model with users might be interesting using a simple interface. In Fig. 7, a convivial graphical user interface based on MATLAB software and using the trained SVR model was developed to evaluate the solubility of 145 solid solutes in $\mathrm{scCO}_{2}$.

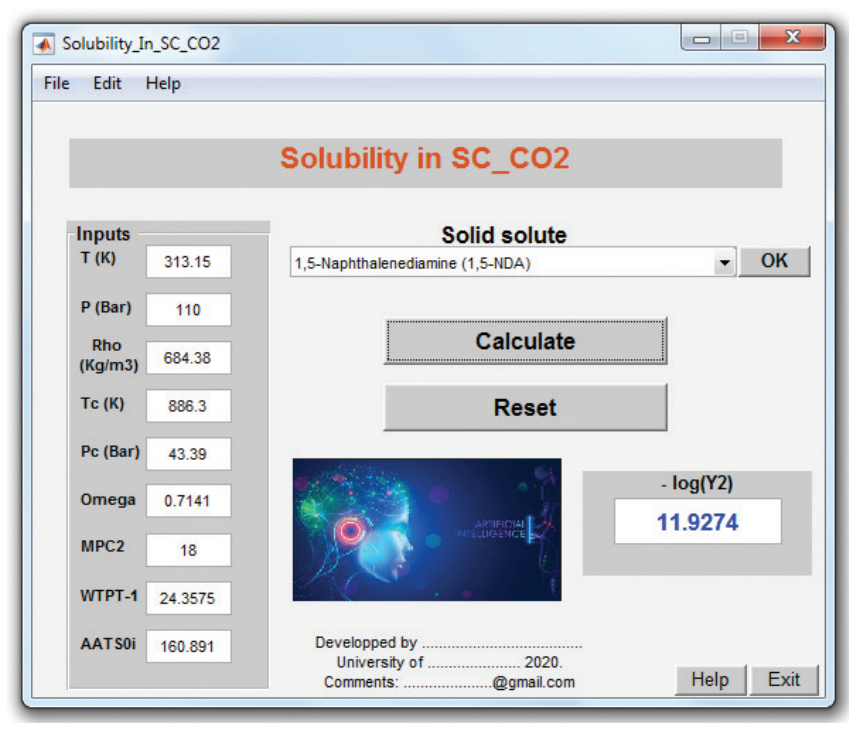

Fig. 7 -A MATLAB calculator to evaluate the solubility of 145 solid solutes in $\mathrm{SCCO}_{2}$ using support vector machine model

\section{Global Sensitivity analysis}

The objective of the global sensitivity analysis is a mathematical technique applied to find which input variable is considered more important for prediction of solubility values. ${ }^{124,125}$ In this work, the cosine amplitude method (CAM) was employed to assess the effect of each input on the output. ${ }^{126}$ The used data pairs build a data array $X$ which are defined as $X=\left\{X_{1}, X_{2}, X_{3}, \ldots, X_{\mathrm{m}}\right\}$, where $X_{\mathrm{i}}$ is a vector of lengths $m$, expressed as: $X_{i}=\left\{x_{i 1}, X_{i 2}, X_{i 3}, \ldots, X_{i m}\right\}$. The $r_{i j}$ values are defined as the strength relationships between the output $x_{\mathrm{i}}$ and input $x_{\mathrm{i}}$ parameters, and can be calculated using Eq. (1).

$$
r_{i j}=\frac{\sum_{k=1}^{m} x_{i k} x_{j k}}{\sqrt{\sum_{k=1}^{m} x_{i j}^{2} \sum_{k=1}^{m} x_{j k}^{2}}}
$$

where $i$ and $k$ are the dimensions of the input matrix $(i=1$ to $3637, k=1$ to $m$ ), $j$ is the dimension of the output vector $(j=1$ to 3637$)$, and $m$ is the number of input parameters $(m=9)$.

The importance of input parameters in QSPR-SVM for solid solute solubility in $\mathrm{SCCO}_{2}$ is shown in Fig. 8. As observed, all parameters have approximately the same effects as well. The results prove that all of the designated input parameters in this study have crucial effects on the solid solute solubility in $\mathrm{scCO}_{2}$, hence, they have been appropriately selected.

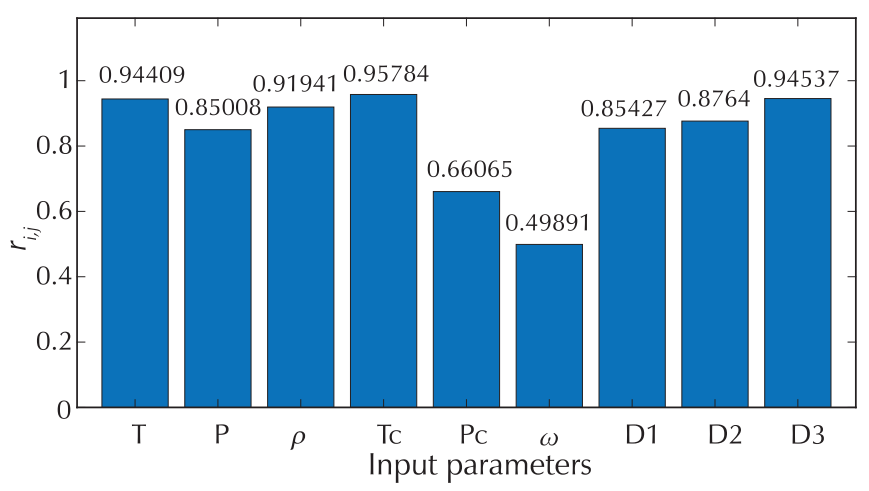

Fig. 8 - Sensitivity analysis between the input variables and the calculated $-\log \left(y_{2}\right)$ in $\mathrm{scCO}_{2}$

\section{Extrapolation capability}

In this section, the extrapolation capability of the proposed model was discussed using the experimental measurements reported in the following papers. ${ }^{127-134}$ The predicted solubility values obtained by the SVR-QSPR model were correlated to the experimental ones of eight systems and also depicted clearly in terms of $\mathrm{scCO}_{2}$ density. The results of the comparison, shown in Figs. (9-16), indicated that the model performed well with a high goodness of fit $R$ during the prediction of the solubility of eight systems, and almost all predicted solubility values of the eight systems fall inside the experimental ones. These results demonstrated clearly that the performance of SVR-QSPR based forecasting model is quite satisfactory. 


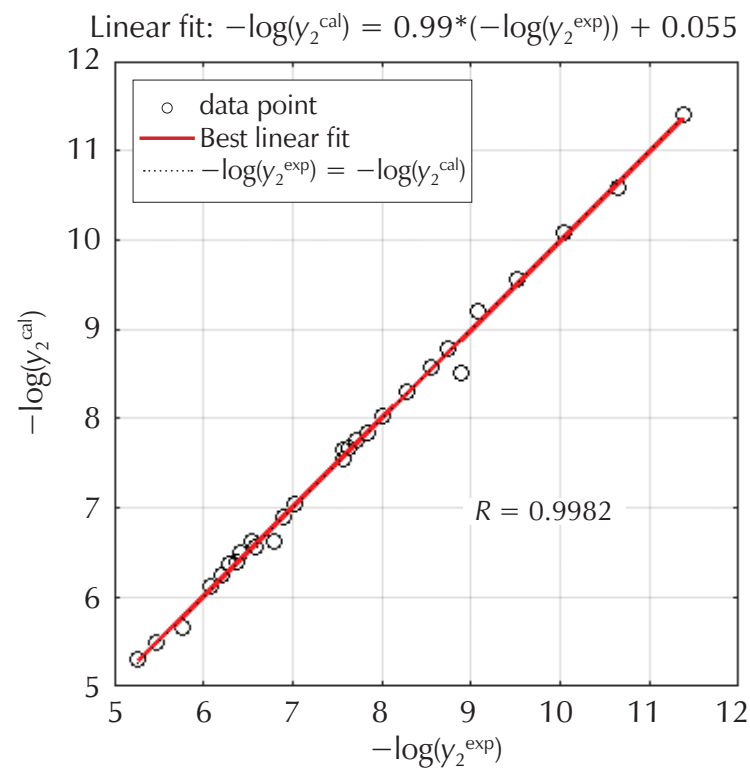

(Solubility of Carvedilol) $R=1 \quad R^{2}=1 \quad$ MAARD $=0.78$

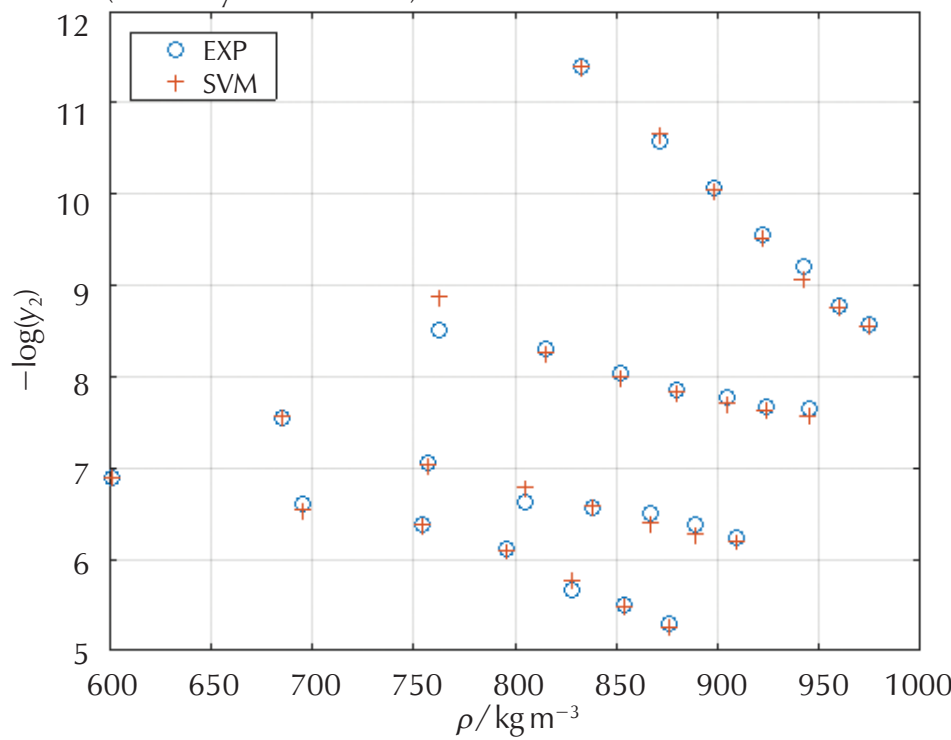

Fig. 9 - a) Plot of predicted solute solubility values in $\mathrm{scCO}_{2}$ vs experimental ones for Carvedilol system, b) Comparison between experimental data ${ }^{127}$ and SVR-QSPR predicted results for Carvedilol system vs $\mathrm{scCO}_{2}$ density
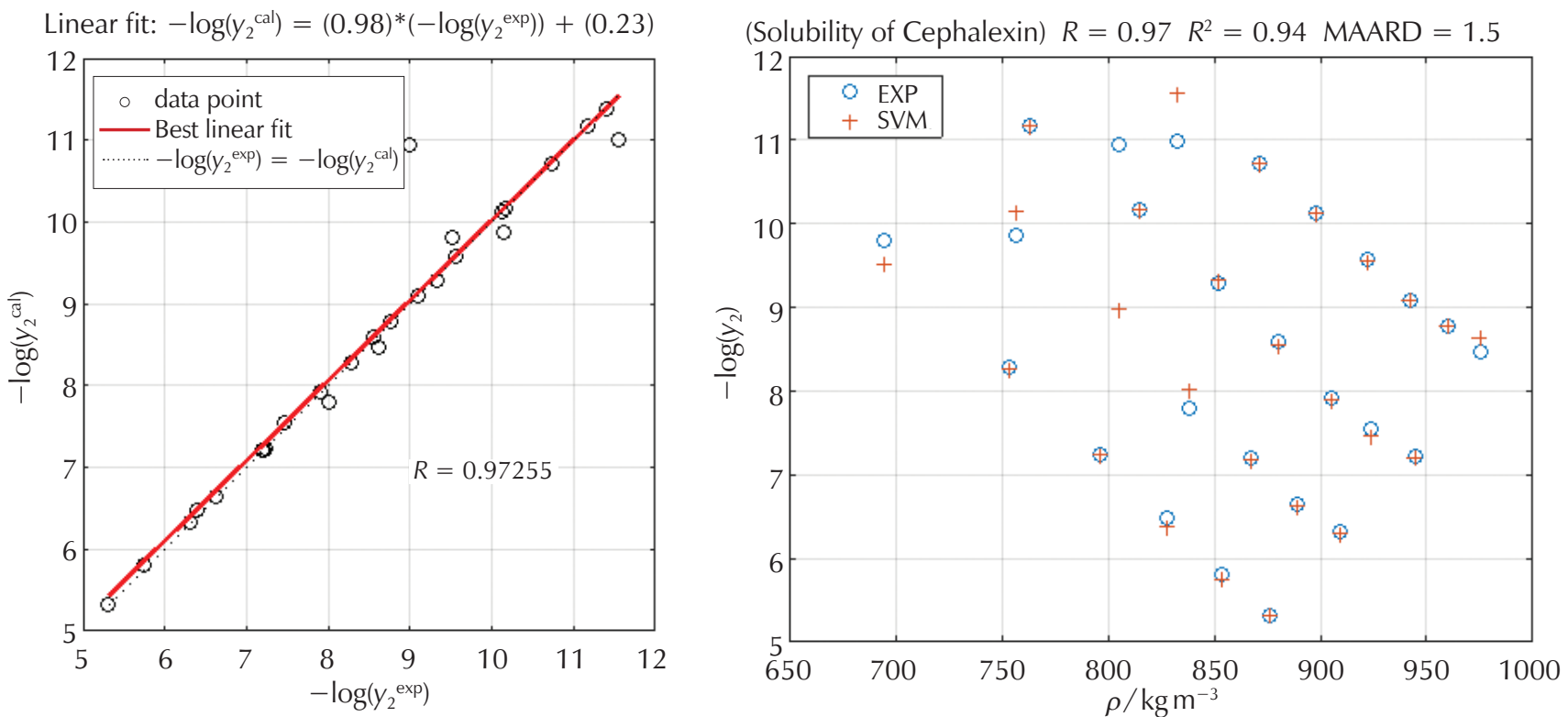

Fig. 10 - a) Plot of predicted solute solubility values in $\mathrm{sCCO}_{2}$ vs experimental ones for Cephalexin system, b) Comparison between experimental data ${ }^{128}$ and SVR-QSPR predicted results for Cephalexin system vs $\mathrm{scCO}_{2}$ density 

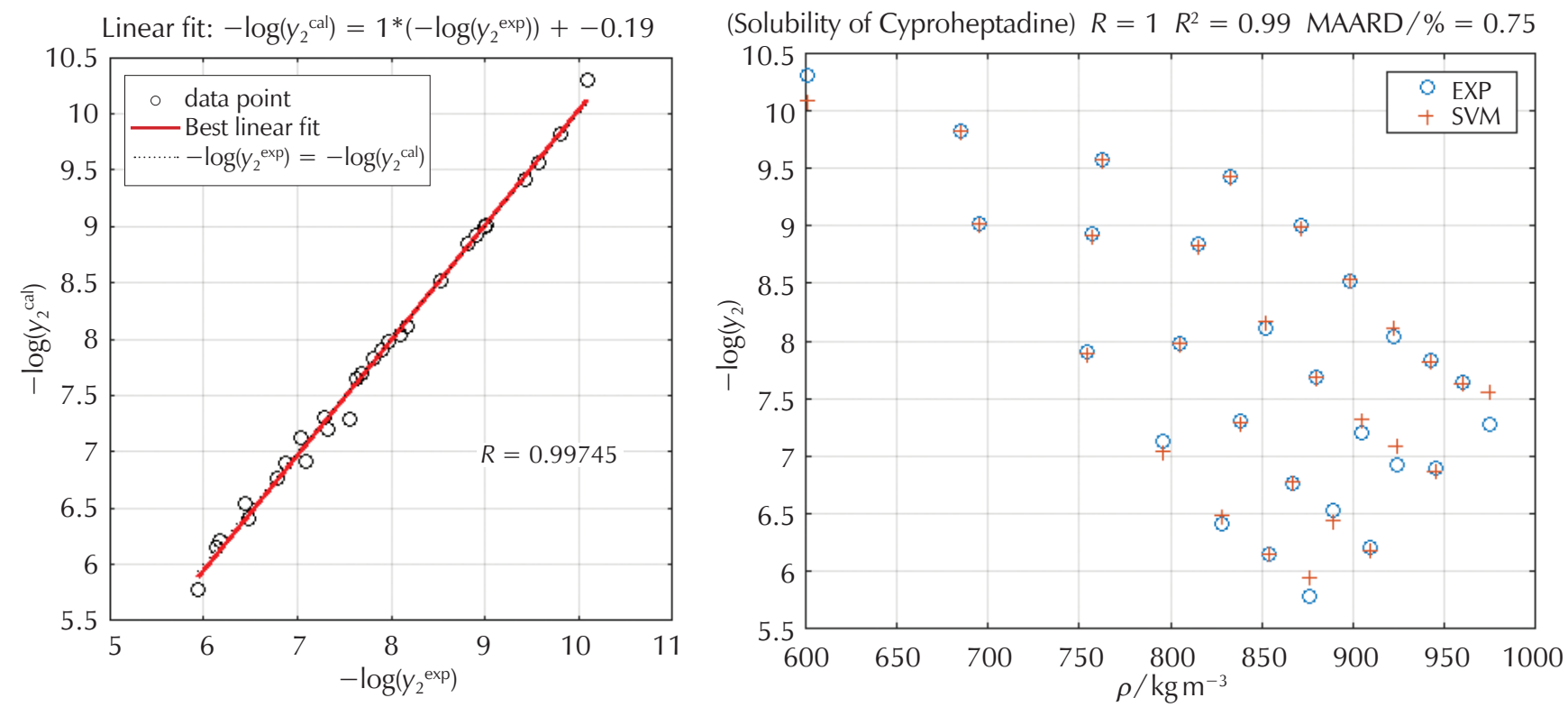

Fig. 11 - a) Plot of predicted solute solubility values in $\mathrm{sCCO}_{2}$ vs experimental ones for Cyproheptadine system, b) Comparison between experimental data ${ }^{129}$ and SVR-QSPR predicted results for Cyproheptadine system vs $\mathrm{sCCO}_{2}$ density
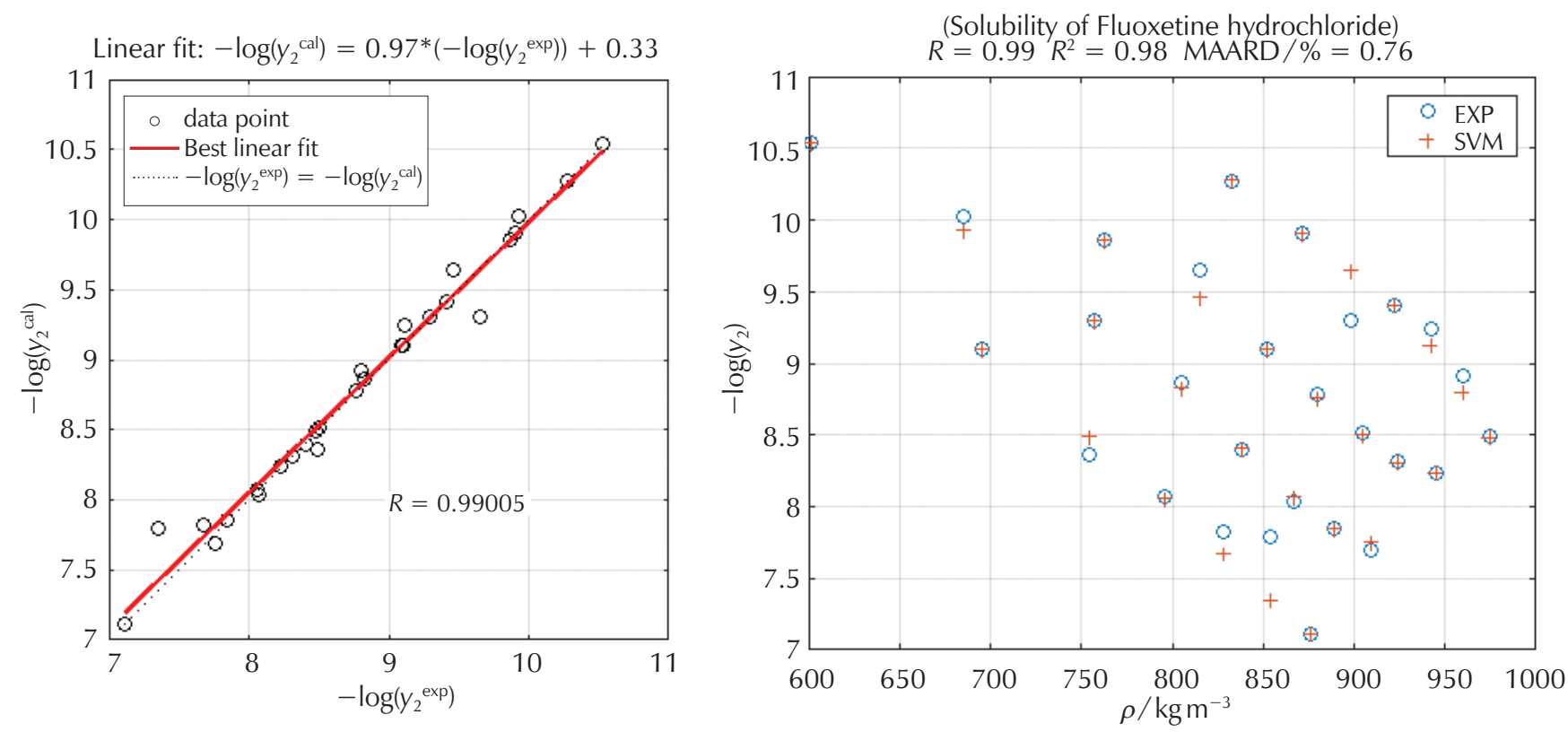

Fig. 12 - a) Plot of predicted solute solubility values in $\mathrm{scCO}_{2}$ vs experimental ones for Fluoxetine hydrochloride system, b) Comparison between experimental data ${ }^{130}$ and SVR-QSPR predicted results for Fluoxetine hydrochloride system vs $\mathrm{scCO}_{2}$ density 

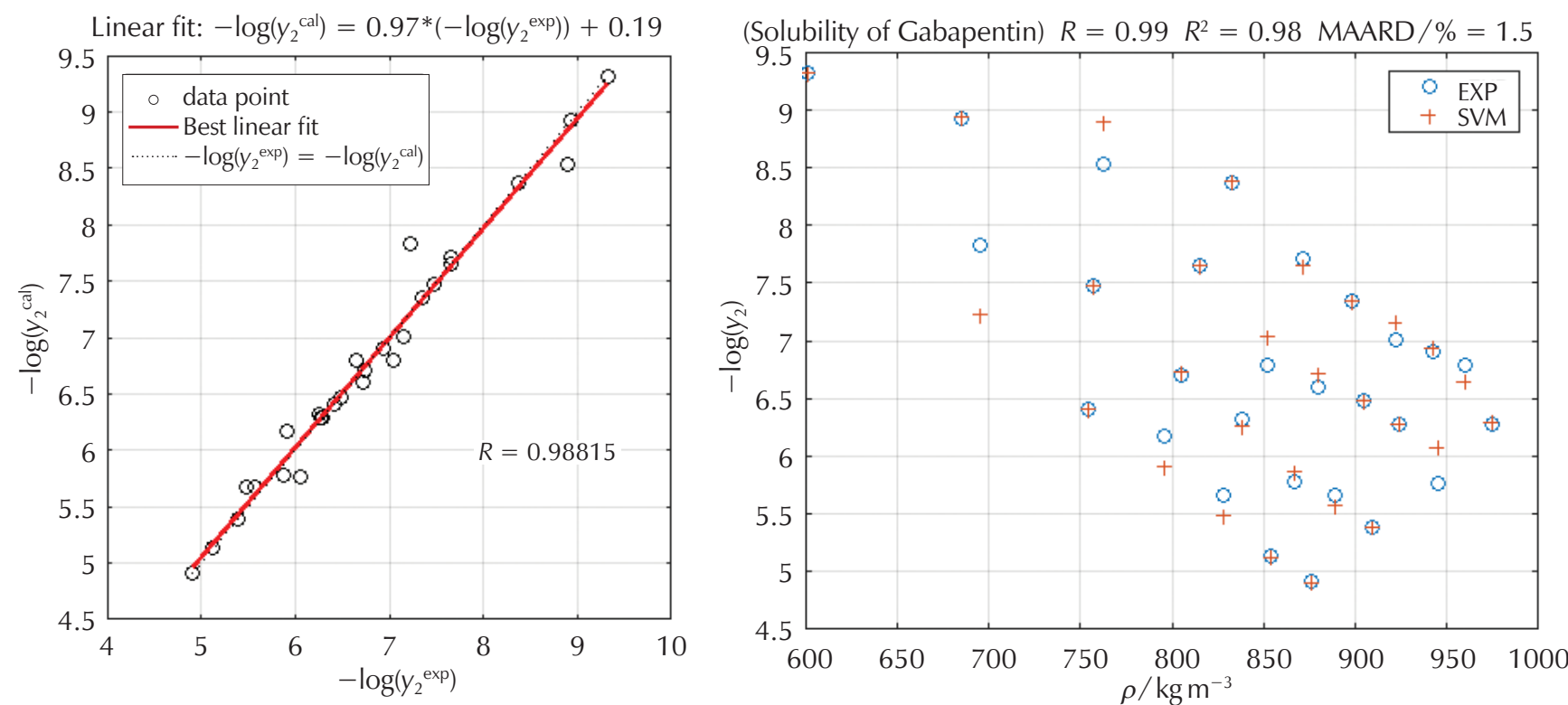

Fig. 13 - a) Plot of predicted solute solubility values in $\mathrm{sCCO}_{2}$ vs experimental ones for Gabapentin system, b) Comparison between experimental data ${ }^{131}$ and SVR-QSPR predicted results for Gabapentin system vs $\mathrm{scCO}_{2}$ density
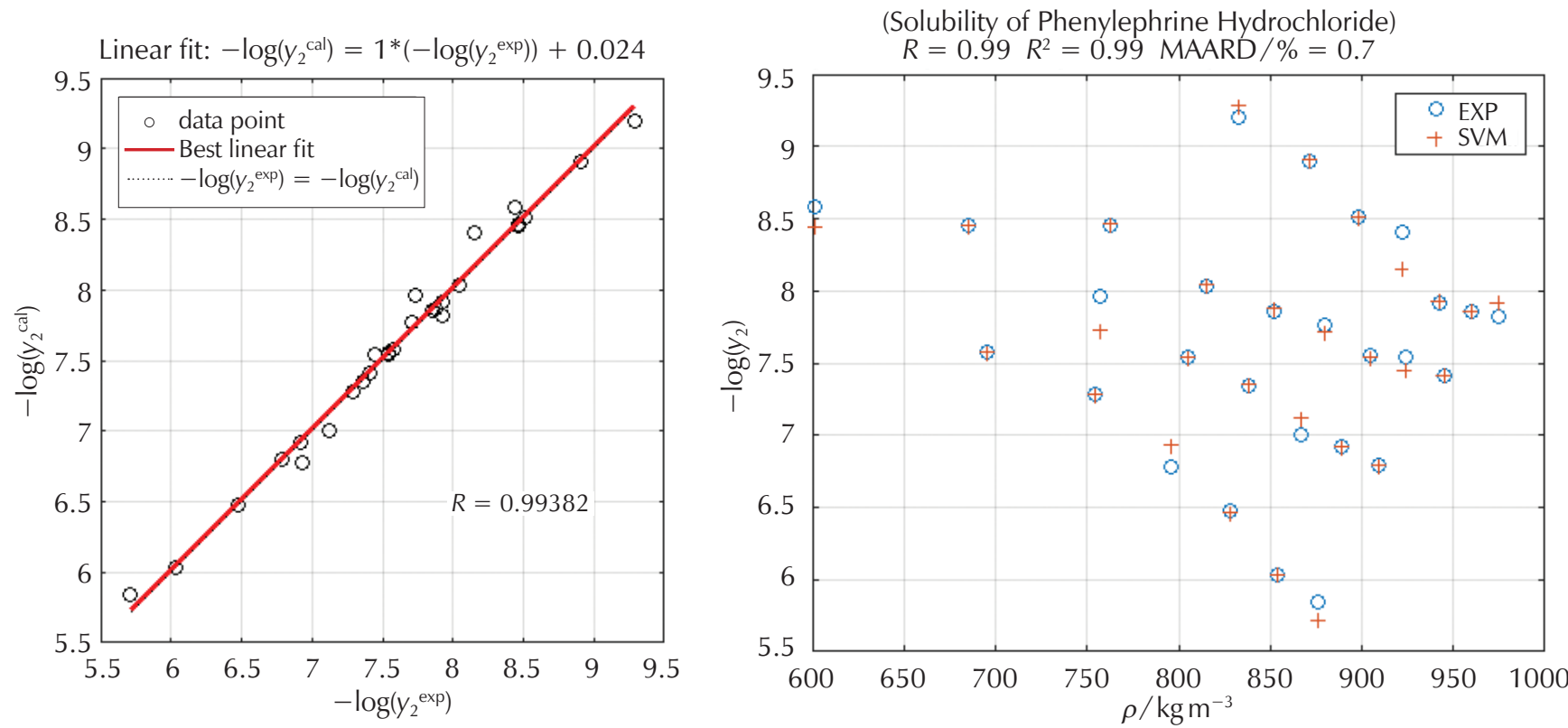

Fig. 14 - a) Plot of predicted solute solubility values in $\mathrm{scCO}_{2}$ vs experimental ones for Phenylephrine Hydrochloride system, b) Comparison between experimental data ${ }^{132}$ and SVR-QSPR predicted results for Phenylephrine Hydrochloride system vs $\mathrm{SCCO}_{2}$ density

\section{Conclusion}

In this study, a comparison was conducted between support vector machine (SVM) and artificial neural network (ANN) to predict non-linear variation of the solubility of 145 different compounds in supercritical carbon dioxide. Results show clearly that coupling the SVR approach with QSPR is more accurate with $R^{2}$ and AARD\% of 0.9857 and $1.345 \%$, respectively, in comparison with ANN-QSPR for estimating the drug solubility in $\mathrm{scCO}_{2}$. The predictive ability index of the optimal model was estimated with a leaveone-out cross-validated coefficient $\left(Q^{2}{ }_{100}\right)$ of 0.9859 .
Based on the calculated statistical parameters, the QSPRSVM has better performance than QSPR-ANN. Therefore, advantageously, the proposed QSPR-SVM as a simple approach to forecasting solid solute solubility in $\mathrm{sCCO}_{2}$ can be used in commercial software in the absence of experimental data. Also, QSPR-SVM modelling for the prediction of solubility of solid solute in $\mathrm{SCCO}_{2}$ provided in this study shows better performance in comparison with the other previous correlations. A sensitivity analysis has been conducted to show the influence of each input parameter on the output variable. All parameters have approximately the same effects as well. 


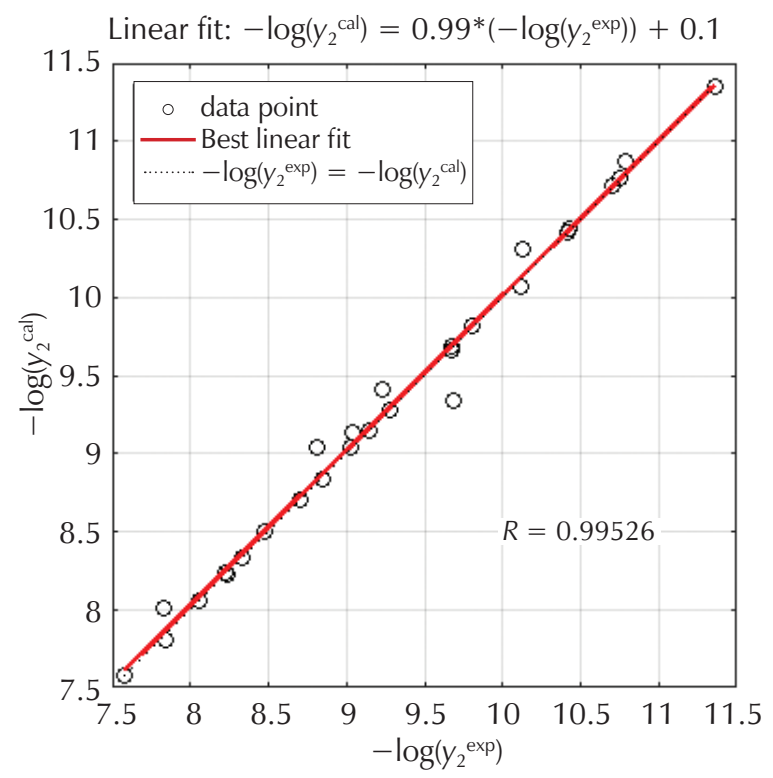

(Solubility of Piroxicam) $R=1 R^{2}=0.99$ MAARD $/ \%=0.57$

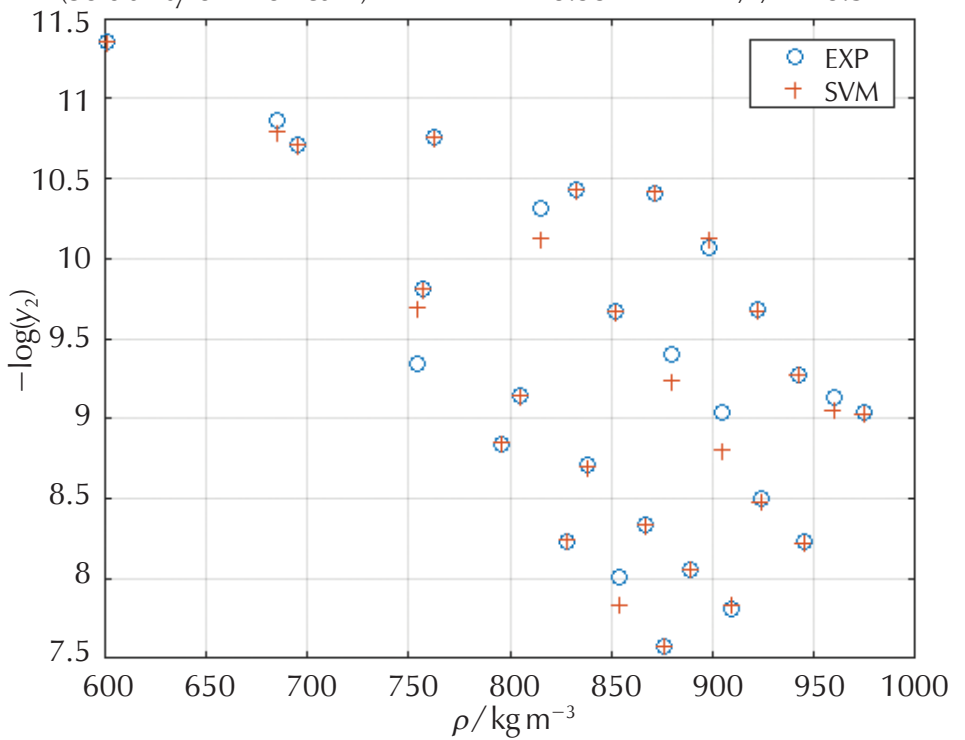

Fig. 15 - a) Plot of predicted solute solubility values in $\mathrm{scCO}_{2}$ vs experimental ones for Piroxicam system, b) Comparison between experimental data ${ }^{133}$ and SVR-QSPR predicted results for Piroxicam system vs $\mathrm{sCCO}_{2}$ density
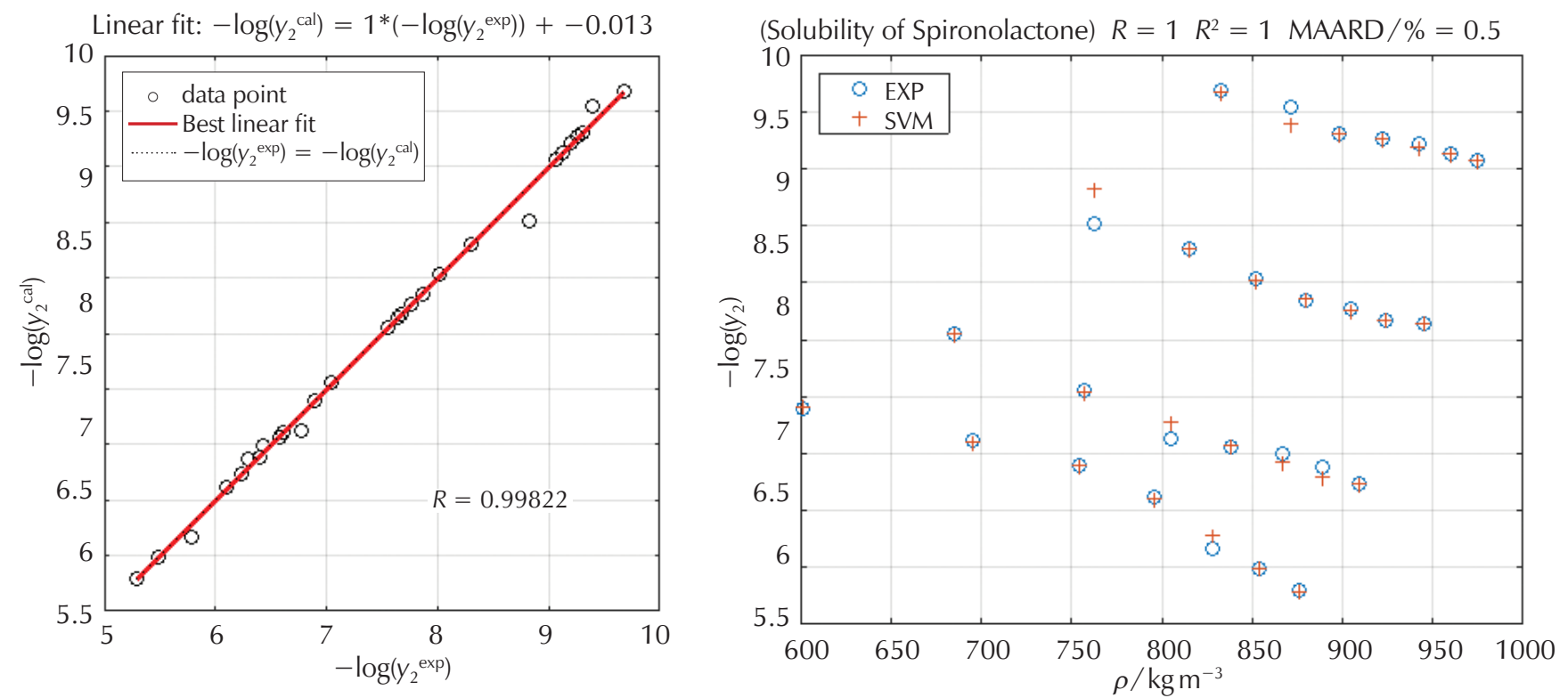

Fig. 16 - a) Plot of predicted solute solubility values in $\mathrm{scCO}_{2}$ vs experimental ones for Spironolactone system, b) Comparison between experimental data ${ }^{134}$ and SVR-QSPR predicted results for Spironolactone system vs $\mathrm{sCCO}_{2}$ density

\section{List of abbreviations}

ANFIS - Adaptive Neuro-Fuzzy Inference System

ANN - Artificial Neural Network

C - Penalising Parameter

FFNN - Feed Forward Neural Network

GA - Genetic Algorithm

GWO - Grey Wolf Optimiser

LS-SVR - Least Square Support Vector Regress

MAARD - Mean Average Absolute Relative Deviation, \%
MSE - Mean Squared Error, \%

QSPR - Quantitative Structure-Property Relationship

$R \quad-$ Correlation Coefficient

RBF - Radial Basis Function

RMSE - Root Mean Square Error, \%

$S-$ Kernel Width Parameter

SC - Supercritical

SVR - Support Vector Regress

$\epsilon$ - Error-Accuracy Parameter 


\section{References}

\section{Literatura}

1. A. J. A. Meirelles, Prediction of solid solute solubility in supercritical $\mathrm{CO}_{2}$ with cosolvents using the CPAEOS, Fluid Phase Equilib. 482 (2019) 1-10, doi: https://doi.org/10.1016/j. fluid.2018.10.020.

2. A. Belghait, C. Si-Moussa, M. Laidi, S. Hanini, Corrélation semi-empirique de solubilité des solutés solides dans le dioxyde de carbone supercritique: étude comparative et proposition d'un nouveau modèle basé sur la densité, Comptes Rendus Chim. 21 (2018) 494-513, doi: https://doi. org/10.1016/j.crci.2018.02.006.

3. A. R. Katritzky, M. Kuanar, S. Slavov, C. D. Hall, M. Karelson, I. Kahn, D. A. Dobchev, Quantitative correlation of physical and chemical properties with chemical structure: utility for prediction, Chem. Rev. 110 (2010) 5714-5789, doi: https:// doi.org/10.1021/cr900238d.

4. A. Abdallah el Hadj, M. Laidi, C. Si-Moussa, S. Hanini, Novel approach for estimating solubility of solid drugs in supercritical carbon dioxide and critical properties using direct and inverse artificial neural network (ANN), Neural Comput. Appl. 28 (2017) 87-99, doi: https://doi.org/10.1007/s00521-0152038-1.

5. A. Z. Hezave, M. Lashkarbolooki, A new simple correlation for calculating solubility of drugs in supercritical carbon dioxide, J. Theor. Comput. Chem. 12 (2013) 1350062, doi: https://doi.org/10.1142/S0219633613500624.

6. M. Abdi-Khanghah, A. Bemani, Z. Naserzadeh, Z. Zhang, Prediction of solubility of $\mathrm{N}$-alkanes in supercritical $\mathrm{CO}_{2}$ using RBF-ANN and MLP-ANN, J. CO2 Util. 25 (2018) 108-119, doi: https://doi.org/10.1016/j.jcou.2018.03.008.

7. B. Mehdizadeh, K. Movagharnejad, A comparative study between LS-SVM method and semi empirical equations for modeling the solubility of different solutes in supercritical carbon dioxide, Chem. Eng. Res. Des. 89 (2011) 24202427, doi: https://doi.org/10.1016/j.cherd.2011.03.017.

8. A. Ray, T. Halder, S. Jena, A. Sahoo, B. Ghosh, S. Mohanty, N. Mahapatra, S. Nayak, Application of artificial neural network (ANN) model for prediction and optimization of coronarin D content in Hedychium coronarium, Ind. Crops Prod. 146 (2020) 112186, doi: https://doi.org/10.1016/j.indcrop.2020.112186.

9. A. Oppio, S. Corsi, Territorial vulnerability and local conflicts perspectives for waste disposals siting. A case study in Lombardy region (Italy), J. Clean. Prod. 141 (2017) 1528-1538, doi: https://doi.org/10.1016/j.jclepro.2016.09.203.

10. W. H. Chen, S. H. Hsu, H. P. Shen, Application of SVM and ANN for intrusion detection, Comput. Oper. Res. 32 (2005) 2617-2634, doi: https://doi.org/10.1016/j.cor.2004.03.019.

11. D. K. Agrafiotis, W. Cedeno, V. S. Lobanov, On the use of neural network ensembles in QSAR and QSPR, J. Chem. Inf. Comput. Sci. 42 (2002) 903-911, doi: https://doi. org/10.1021/ci0203702.

12. T. N. G. Borhani, A. Afzali, M. Bagheri, QSPR estimation of the auto-ignition temperature for pure hydrocarbons, Process Saf. Environ. Prot. 103 (2016) 115-125, doi: https://doi. org/10.1016/j.psep.2016.07.004.

13. D. L. Sparks, R. Hernandez, L. A. Estévez, Evaluation of density-based models for the solubility of solids in supercritical carbon dioxide and formulation of a new model, Chem. Eng. Sci. 63 (2008) 4292-4301, doi: https://doi.org/10.1016/j. ces.2008.05.031.

14. K. Khimeche, P. Alessi, I. Kikic, A. Dahmani, Solubility of diamines in supercritical carbon dioxide. Experimental determination and correlation, J. Supercrit. Fluids 41 (2007) 10-19, doi: https://doi.org/10.1016/j.supflu.2006.09.004.
15. Y. M. Chen, Y. P. Chen, Measurements for the solid solubilities of antipyrine, 4-aminoantipyrine and 4-dimethylaminoantipyrine in supercritical carbon dioxide, Fluid Phase Equilib. 282 (2009) 82-87, doi: https://doi.org/10.1016/j. fluid.2009.04.019.

16. Z. Huang, S. Kawi, Y. C. Chiew, Solubility of cholesterol and its esters in supercritical carbon dioxide with and without cosolvents, J. Supercrit. Fluids 30 (2004) 25-39, doi: https:// doi.org/10.1016/S0896-8446(03)00116-5

17. M. Hojjati, Y. Yamini, M. Khajeh, A. Vatanara, Solubility of some statin drugs in supercritical carbon dioxide and representing the solute solubility data with several density-based correlations, J. Supercrit. Fluids 41 (2007) 187-194, doi: https://doi.org/10.1016/j.supflu.2006.10.006.

18. Y. Yamini, N. Bahramifar, Solubility of polycyclic aromatic hydrocarbons in supercritical carbon dioxide, J. Chem. Eng. Data 45 (2000) 53-56, doi: https://doi.org/10.1021/ je990129s.

19. D. L. Sparks, R. Hernandez, L. A. Estévez, N. Meyer, T. French, Solubility of Azelaic Acid in Supercritical Carbon Dioxide, J. Chem. Eng. Data 52 (2007) 1246-1249, doi: https://doi. org/10.1021/je600572z.

20. A. Garmroodi, J. Hassan, Y. Yamini, Solubilities of the drugs benzocaine, metronidazole benzoate, and naproxen in supercritical carbon dioxide, J. Chem. Eng. Data 49 (2004) 709-712, doi: https://doi.org/10.1021/je020218w.

21. K. W. Cheng, M. Tang, Y. P. Chen, Solubilities of benzoin, propyl 4-hydroxybenzoate and mandelic acid in supercritical carbon dioxide, Fluid Phase Equilib. 201 (2002) 79-96, doi: https://doi.org/10.1016/S0378-3812(02)00070-5.

22. M. Asghari-Khiavi, Y. Yamini, Solubility of the Drugs Bisacodyl, Methimazole, Methylparaben, and lodoquinol in Supercritical Carbon Dioxide, J. Chem. Eng. Data 1 (2003) 61-65, doi: https://doi.org/10.1021/JE020080H.

23. M. Johannsen, G. Brunner, Solubilities of the xanthines caffeine, theophylline and theobromine in supercritical carbon dioxide, Fluid Phase Equilib. 95 (1994) 215-226, doi: https://doi.org/10.1016/0378-3812(94)80070-7.

24. P. Coimbra, C. M. M. Duarte, H. C. De Sousa, Cubic equation-of-state correlation of the solubility of some anti-inflammatory drugs in supercritical carbon dioxide, Fluid Phase Equilib. 239 (2006) 188-199, doi: https://doi.org/10.1016/j. fluid.2005.11.028.

25. Y. M. Chen, P. C. Lin, M. Tang, Y. P. Chen, Solid solubility of antilipemic agents and micronization of gemfibrozil in supercritical carbon dioxide, J. Supercrit. Fluids 52 (2010) 175182, doi: https://doi.org/10.1016/j.supflu.2009.12.012.

26. P. Coimbra, D. Fernandes, P. Ferreira, M. H. Gil, H. C. de Sousa, Solubility of Irgacure ${ }^{\circledR} 2959$ photoinitiator in supercritical carbon dioxide: Experimental determination and correlation, J. Supercrit. Fluids 45 (2008) 272-281, doi: https://doi. org/10.1016/j.supflu.2008.01.014.

27. A. G. Reveco-Chilla, A. L. Cabrera, J. C. de la Fuente, F. C. Zacconi, J. M. del Valle, L. M. Valenzuela, Solubility of menadione and dichlone in supercritical carbon dioxide, Fluid Phase Equilib. 423 (2016) 84-92, doi: https://doi. org/10.1016/j.fluid.2016.04.001.

28. Y. Yamini, J. Arab, M. Asghari-khiavi, Solubilities of phenazopyridine, propranolol, and methimazole in supercritical carbon dioxide, J. Pharm. Biomed. Anal. 32 (2003) 181-187, doi: https://doi.org/10.1016/S0731-7085(03)00016-5.

29. P. Kotnik, M. Škerget, Z. Knez, Solubility of Nicotinic Acid and Nicotinamide in Carbon Dioxide at $T=(313.15$ to 373.15) $\mathrm{K}$ and $p=$ (5 to 30) MPa: Experimental Data and Correlation, J. Chem. Eng. Data 56 (2011) 338-343, doi: https://doi.org/10.1021/je100697a.

30. M. Khamda, M. H. Hosseini, M. Rezaee, Measurement and 
correlation solubility of cefixime trihydrate and oxymetholone in supercritical carbon dioxide $\left(\mathrm{CO}_{2}\right)$, J. Supercrit. Fluids 73 (2013) 130-137, doi:https://doi.org/10.1016/j. supflu.2012.09.006.

31. Z. Huang, Y.-H. Guo, H. Miao, L.-J. Teng, Solubility of progesterone in supercritical carbon dioxide and its micronization through RESS, Powder Technol. 258 (2014) 66-77, doi: https://doi.org/10.1016/j.powtec.2014.03.009.

32. J. T. Paula, I. M. O. Sousa, M. A. Foglio, F. A. Cabral, Solubility of protocatechuic acid, sinapic acid and chrysin in supercritical carbon dioxide, J. Supercrit. Fluids 112 (2016) 89-94, doi: https://doi.org/10.1016/j.supflu.2016.02.014.

33. J. García-González, M. J. Molina, F. Rodríguez, F. Mirada, Solubilities of Phenol and Pyrocatechol in Supercritical Carbon Dioxide, J. Chem. Eng. Data 46 (4) (2001) 918-921, doi: https://doi.org/10.1021/JE0003795.

34. J. García-González, M. J. Molina, F. Rodríguez, F. Mirada, Solubilities of phenol and pyrocatechol in supercritical carbon dioxide, J. Chem. Eng. Data 46 (2001) 918-921, doi: https:// doi.org/10.1021/je0003795.

35. Y. Yamini, M. R. Fat'Hi, N. Alizadeh, M. Shamsipur, Solubility of dihydroxybenzene isomers in supercritical carbon dioxide, Fluid Phase Equilib. 152 (1998) 299-305, doi: https:// doi.org/10.1016/S0378-3812(98)00385-9.

36. F. Zabihi, M. Mirzajanzadeh, J. Jia, Y. Zhao, Measurement and calculation of solubility of quinine in supercritical carbon dioxide, Chinese J. Chem. Eng. 25 (2017) 641-645, doi: https://doi.org/10.1016/j.cjche.2016.10.003.

37. J. Ke, C. Mao, M. Zhong, B. Han, H. Yan, Solubilities of salicylic acid in supercritical carbon dioxide with ethanol cosolvent, J. Supercrit. Fluids 9 (1996) 82-87, doi: https://doi. org/10.1016/S0896-8446(96)90002-9.

38. G. I. Burgos-Solórzano, J. F. Brennecke, M. A. Stadtherr, Solubility measurements and modeling of molecules of biological and pharmaceutical interest with supercritical $\mathrm{CO}_{2}$, Fluid Phase Equilib. 220 (2004) 57-69, doi: https://doi. org/10.1016/j.fluid.2004.01.036.

39. S. J. Nejad, R. Mohammadikhah, H. Abolghasemi, M. A. Moosavian, M. G. Maragheh, A Novel equation of state (EOS) for prediction of solute solubility in supercritical carbon dioxide: Experimental determination and correlation, Can. J. Chem. Eng. 87 (2009) 930-938, doi: https://doi.org/10.1002/ cjce. 20232 .

40. S. Y. Huang, M. Tang, S. L. Ho, Y. P. Chen, Solubilities of $\mathrm{N}$-phenylacetamide, 2-methyl-N-phenylacetamide and 4-methyl- $N$-phenylacetamide in supercritical carbon dioxide, J. Supercrit. Fluids 42 (2007) 165-171, doi: https://doi. org/10.1016/j.supflu.2007.04.001.

41. G. Tian, J. Jin, Z. Zhang, J. Guo, Solubility of mixed solids in supercritical carbon dioxide, Fluid Phase Equilib. 251 (2007) 47-51, doi: https://doi.org/10.1016/j.fluid.2006.11.002.

42. K. Tamura, R. S. Alwi, T. Tanaka, K. Shimizu, Solubility of 1 -aminoanthraquinone and 1-nitroanthraquinone in supercritical carbon dioxide, J. Chem. Thermodyn. 104 (2017) 162-168, doi: https://doi.org/10.1016/j.jct.2016.09.032.

43. R. Murga, M. T. Sanz, S. Beltrán, J. L. Cabezas, Solubility of three hydroxycinnamic acids in supercritical carbon dioxide, J. Supercrit. Fluids 27 (2003) 239-245, doi: https://doi. org/10.1016/S0896-8446(02)00265-6.

44. M. Johannsen, G. Brunner, Solubilities of the Fat-Soluble Vitamins A, D, E, and $K$ in Supercritical Carbon Dioxide, J. Chem. Eng. Data 42 (1997) 106-111, doi: https://doi. org/10.1021/je960219m.

45. K.-L. Tsai, F.-N. Tsai, Solubilities of Methylbenzoic Acid Isomers in Supercritical Carbon Dioxide, J. Chem. Eng. Data 40 (1995) 264-266, doi: https://doi.org/10.1021/je00017a057.

46. H. Asiabi, Y. Yamini, F. Latifeh, A. Vatanara, Solubilities of four macrolide antibiotics in supercritical carbon dioxide and their correlations using semi-empirical models, J. Supercrit. Fluids 104 (2015) 62-69, doi: https://doi.org/10.1016/j.supflu.2015.05.018.

47. V. Pauchon, Z. Cissé, M. Chavret, J. Jose, A new apparatus for the dynamic determination of solid compounds solubility in supercritical carbon dioxide: Solubility determination of triphenylmethane, J. Supercrit. Fluids 32 (2004) 115-121, doi: https://doi.org/10.1016/j.supflu.2004.03.003.

48. G. Sodeifian, S. A. Sajadian, F. Razmimanesh, Solubility of an antiarrhythmic drug (amiodarone hydrochloride) in supercritical carbon dioxide: Experimental and modeling, Fluid Phase Equilib. 450 (2017) 149-159, doi: https://doi. org/10.1016/j.fluid.2017.07.015.

49. K. Tamura, R. S. Alwi, Solubility of anthraquinone derivatives in supercritical carbon dioxide, Dye. Pigment. 113 (2015) 351-356, doi: https://doi.org/10.1016/j.dyepig.2014.09.003.

50. J. Jin, Y. Wang, H. Liu, Z. Zhang, Determination and calculation of solubility of bisphenol A in supercritical carbon dioxide, Chem. Eng. Res. Des. 91 (2013) 158-164, doi: https:// doi.org/10.1016/j.cherd.2012.06.013.

51. J. Jin, Y. Ning, K. Hu, H. Wu, Z. Zhang, Solubility of p -Nitroaniline in Supercritical Carbon Dioxide with and without Mixed Cosolvents, J. Chem. Eng. Data 58 (2013) 14641469, doi: https://doi.org/10.1021/je300987d.

52. S. Ismadji, Solubility of methyl salicylate in supercritical carbon dioxide at several temperatures, J. Chem. Eng. Data 53 (2008) 2207-2210, doi: https://doi.org/10.1021/je800476n.

53. S. Marceneiro, P. Coimbra, M. E. M. Braga, A. M. A. Dias, H. C. De Sousa, Measurement and correlation of the solubility of juglone in supercritical carbon dioxide, Fluid Phase Equilib. 311 (2011) 1-8, doi: https://doi.org/10.1016/j.fluid.2011.08.024.

54. J. Yau, F. Tsai, Solubilities of 1-Eicosanol and Eicosanoic Acid in Supercritical Carbon Dioxide from 308.2 to $328.2 \mathrm{~K}$ at Pressures to 21.26 MPa, J. Chem. Eng. Data 39 (1994) 827829, doi: https://doi.org/10.1021/je00016a042.

55. A. Kramer, G. Thodos, Solubility of I-Octadecanol and Stearic Acid in Supercritical Carbon Dioxide, J. Chem. Eng. Data 34 (2) (1989) 184-187, doi: https://doi.org/10.1021/ je00056a011.

56. H. A. Martinez-Correa, D. C. A. Gomes, S. L. Kanehisa, F. A. Cabral, Measurements and thermodynamic modeling of the solubility of squalene in supercritical carbon dioxide, J. Food Eng. 96 (2010) 43-50, doi: https://doi.org/10.1016/j.jfoodeng.2009.06.041.

57. I. Goodarznia, F. Esmaeilzadeh, Solubility of an anthracene, phenanthrene, and carbazole mixture in supercritical carbon dioxide, J. Chem. Eng. Data 47 (2002) 333-338, doi: https://doi.org/10.1021/je010093f.

58. M. Ashraf-Khorassani, M. T. Combs, L. T. Taylor, F. K. Schweighardt, P. S. Mathias, Solubility study of sulfamethazine and sulfadimethoxine in supercritical carbon dioxide, fluoroform, and subcritical freon 134A, J. Chem. Eng. Data 42 (1997) 636-640, doi: https://doi.org/10.1021/je960402f.

59. J. W. Hampson, A Recirculating Equilibrium Procedure for Determining Organic Compound Solubility in Supercritical Fluids. Anthracene in Carbon Dioxide, J. Chem. Eng. Data 41 (1996) 97-100, doi: https://doi.org/10.1021/je950167l.

60. A. Cortesi, I. Kikic, P. Alessi, G. Turtoi, S. Garnier, Effect of chemical structure on the solubility of antioxidants in supercritical carbon dioxide : experimental data and correlation, J. Supercritic. Fluid. 14 (2) (1999) 139-144, doi: https://doi. org/10.1016/S0896-8446(98)00119-3.

61. L. Barna, J. Blanchard, E. Rauzy, C. Berro, D. Lyon, Solubility of Flouranthene, Chrysene, and Triphenylene in Super- 
critical Carbon Dioxide, J. Chem. Eng. Data 41 (6) (1996) 1466-1469, doi: https://doi.org/10.1021/je960189n.

62. J. Gregorowicz, Solubilities of lactic acid and 2-hydroxyhexanoic acid in supercritical $\mathrm{CO}_{2}$, Fluid Phase Equilib. 166 (1999) 39-46, doi: https://doi.org/10.1016/S03783812(99)00283-6.

63. E. Reverchon, P. Russo, A. Stassi, Solubilities of Solid Octacosane and Triacontane in Supercritical Carbon Dioxide, J. Chem. Eng. Data 38 (1993) 458-460, doi: https://doi. org/10.1021/je00011a034.

64. C. Garlapati, G. Madras, Solubilities of hexadecanoic and octadecanoic acids in supercritical CO with and without cosolvents, J. Chem. Eng. Data 53 (2008) 2913-2917, doi: https://doi.org/10.1021/je8007149.

65. H. Xing, Y. Yang, B. Su, M. Huang, Q. Ren, Solubility of Artemisinin in Supercritical Carbon Dioxide, J. Chem. Eng. Data 48 (2) (2003) 330-332, doi: https://doi.org/10.1021/ je025575l.

66. S. H. Cheng, F. C. Yang, Y. H. Yang, C. C. Hu, W. T. Chang, Measurements and modeling of the solubility of ergosterol in supercritical carbon dioxide, J. Taiwan Inst. Chem. Eng. 44 (2013) 19-26, doi: https://doi.org/10.1016/j. jtice.2012.09.001.

67. S. L. J. Yun, K. K. Liong, G. S. Gurdial, N. R. Foster, Solubility of cholesterol in supercritical carbon dioxide, Ind. Eng. Chem. Res. 30 (1991) 2476-2482, doi: https://doi.org/10.1021/ ie00059a018.

68. S. J. Macnaughton, N. R. Foster, Solubility of DDT and 2,4-D in Supercritical Carbon Dioxide and Supercritical Carbon Dioxide Saturated with Water, Ind. Eng. Chem. Res. 33 (1994) 2757-2763, doi: https://doi.org/10.1021/ie00035a027.

69. R. Murga, M. T. Sanz, S. Beltrán, J. L. Cabezas, Solubility of some phenolic compounds contained in grape seeds, in supercritical carbon dioxide, J. Supercrit. Fluids 23 (2002) 113121, doi: https://doi.org/10.1016/S0896-8446(02)00033-5.

70. S. Marceneiro, M. E. M. Braga, A. M. A. Dias, H. C. De Sousa, Measurement and Correlation of 1,4-Naphthoquinone and of Plumbagin Solubilities in Supercritical Carbon Dioxide, J. Chem. Eng. Data 56 (11) (2011) 4173-4182, doi: https:// doi.org/10.1021/je200675g.

71. P. Coutsikos, K. Magoulas, D. Tassios, Solubilities of $p$-Quinone and 9,10 -Anthraquinone in Supercritical Carbon Dioxide, J. Chem. Eng. Data 42 (1997) 463-466, doi: https:// doi.org/10.1021/je960309r.

72. R. Murga, M. T. Sanz, S. Beltrán, J. L. Cabezas, Solubility of syringic and vanillic acids in supercritical carbon dioxide, J. Chem. Eng. Data 49 (2004) 779-782, doi: https://doi. org/10.1021/je034129a.

73. S. Bristow, B. Y. Shekunov, P. York, Solubility Analysis of Drug Compounds in Supercritical Carbon Dioxide Using Static and Dynamic Extraction Systems, Ind. Eng. Chem. Res. 40 (2001) 1732-1739, doi: https://doi.org/10.1021/ie0002834.

74. J. Shi, M. Khatri, S. J. Xue, G. S. Mittal, Y. Ma, D. Li, Solubility of lycopene in supercritical CO2 fluid as affected by temperature and pressure, Sep. Purif. Technol. 66 (2009) 322-328, doi: https://doi.org/10.1016/j.seppur.2008.12.012..

75. E. Kosal, C. H. Lee, G. D. Holder, Solubility of progesterone, testosterone, and cholesterol in supercritical fluids, J. Supercrit. Fluids 5 (1992) 169-179, doi: https://doi. org/10.1016/0896-8446(92)90004-4.

76. N. R. Foster, S. L. J. Yun, S. S. T. Ting, Solubility of oleic acid in supercritical carbon dioxide, J. Supercrit. Fluids 4 (1991) 127-130, doi: https://doi.org/10.1016/08968446(91)90041-4.

77. J. P. Coelho, G. P. Naydenov, D. S. Yankov, R. P. Stateva, Experimental measurements and correlation of the solubility of three primary amides in supercritical $\mathrm{CO}_{2}$ : Acetanilide, pro- panamide, and butanamide, J. Chem. Eng. Data 58 (2013) 2110-2115, doi: https://doi.org/10.1021/je400357t.

78. Y. P. Chen, Y. M. Chen, M. Tang, Solubilities of cinnamic acid, phenoxyacetic acid and 4-methoxyphenylacetic acid in supercritical carbon dioxide, Fluid Phase Equilib. 275 (2009) 33-38, doi: https://doi.org/10.1016/j.fluid.2008.09.009.

79. N. Lamba, R. C. Narayan, J. Modak, G. Madras, Solubilities of 10-undecenoic acid and geraniol in supercritical carbon dioxide, J. Supercrit. Fluids 107 (2016) 384-391, doi: https:// doi.org/10.1016/j.supflu.2015.09.026.

80. H. Higashi, Y. Iwai, K. Miyazaki, Y. Ogino, M. Oki, Y. Arai, Measurement and correlation of solubilities for trifluoromethylbenzoic acid isomers in supercritical carbon dioxide, J. Supercrit. Fluids 33 (2005) 15-20, doi: https://doi. org/10.1016/j.supflu.2004.03.006.

81. H. Perrotin-Brunel, M. J. E. Van Roosmalen, M. C. Kroon, J. Van Spronsen, G. J. Witkamp, C. J. Peters, Solubility of cannabinol in supercritical carbon dioxide, J. Chem. Eng. Data 55 (2010) 3704-3707, doi: https://doi.org/10.1021/ je100245n

82. J. P. Coelho, K. Bernotaityte, M. A. Miraldes, A. F. Mendonça, R. P. Stateva, Solubility of ethanamide and 2-propenamide in supercritical carbon dioxide. Measurements and correlation, J. Chem. Eng. Data 54 (2009) 2546-2549, doi: https://doi. org/10.1021/je900109b.

83. J. Lim, H. Kim, H. K. Cho, M. S. Shin, Solubility of hinokitiol in supercritical fluids; measurement and correlation, Korean J. Chem. Eng. 28 (2011) 2319-2323, doi: https://doi. org/10.1007/s11814-011-0112-7.

84. M. S. Shin, H. Kim, Solubility of iodopropynyl butylcarbamate in supercritical carbon dioxide, Fluid Phase Equilib. 270 (2008) 45-49, doi: https://doi.org/10.1016/j.fluid.2008.05.010.

85. J. Fan, Y. Hou, W. Wu, J. Zhang, S. Ren, X. Chen, Levulinic acid solubility in supercritical carbon dioxide with and without ethanol as cosolvent at different temperatures, J. Chem. Eng. Data 55 (2010) 2316-2321, doi: https://doi.org/10.1021/ je900727r.

86. S. N. Reddy, G. Madras, Solubilities of Benzene Derivatives in Supercritical Carbon Dioxide, J. Chem. Eng. Data 56 (2011) 1695-1699, doi: https://doi.org/10.1021/je100863p.

87. H. C. De Sousa, M. S. Costa, P. Coimbra, A. A. Matias, C. M. M. Duarte, Experimental determination and correlation of meloxicam sodium salt solubility in supercritical carbon dioxide, J. Supercrit. Fluids 63 (2012) 40-45, doi: https://doi. org/10.1016/j.supflu.2011.12.004.

88. R. Ch, C. Garlapati, G. Madras, Solubility of n-(4-ethoxyphenyl)ethanamide in supercritical carbon dioxide, J. Chem. Eng. Data 55 (2010) 1437-1440, doi: https://doi. org/10.1021/je900614f.

89. G. Sodeifian, N. Saadati Ardestani, S. A. Sajadian, H. S. Panah, Measurement, correlation and thermodynamic modeling of the solubility of Ketotifen fumarate (KTF) in supercritical carbon dioxide: Evaluation of PCP-SAFT equation of state, Fluid Phase Equilib. 458 (2018) 102-114, doi: https://doi. org/10.1016/j.fluid.2017.11.016.

90. G. Sodeifian, S. A. Sajadian, Experimental measurement of solubilities of sertraline hydrochloride in supercritical carbon dioxide with/without menthol: Data correlation with a pressure of about 60, J. Supercrit. Fluids 149 (2019) 79-87, doi: https://doi.org/10.1016/j.supflu.2019.03.020.

91. G. Sodeifian, S. A. Sajadian, N. S. Ardestani, Determination of solubility of Aprepitant (an antiemetic drug for chemotherapy) in supercritical carbon dioxide: Empirical and thermodynamic models, J. Supercrit. Fluids 128 (2017) 102-111, doi: https://doi.org/10.1016/j.supflu.2017.05.019.

92. G. Sodeifian, N. Saadati Ardestani, S. A. Sajadian, H. Soltani 
Panah, Experimental measurements and thermodynamic modeling of Coumarin-7 solid solubility in supercritical carbon dioxide: Production of nanoparticles via RESS method, Fluid Phase Equilib. 483 (2019) 122-143, doi: https://doi. org/10.1016/j.fluid.2018.11.006.

93. G. Sodeifian, S. A. Sajadian, Solubility measurement and preparation of nanoparticles of an anticancer drug (Letrozole) using rapid expansion of supercritical solutions with solid COsolvent (RESS-SC), J. Supercrit. Fluids 133 (2018) 239-252, doi: https://doi.org/10.1016/j.supflu.2017.10.015.

94. G. Sodeifian, F. Razmimanesh, S. A. Sajadian, Solubility measurement of a chemotherapeutic agent (Imatinib mesylate) in supercritical carbon dioxide: Assessment of new empirical model, J. Supercrit. Fluids 146 (2019) 89-99, doi: https:// doi.org/10.1016/j.supflu.2019.01.006.

95. G. Sodeifian, R. Detakhsheshpour, S. A. Sajadian, Experimental study and thermodynamic modeling of Esomeprazole (proton-pump inhibitor drug for stomach acid reduction) solubility in supercritical carbon dioxide, J. Supercrit. Fluids 154 (2019) 104606, doi: https://doi.org/10.1016/j.supflu.2019.104606.

96. G. Sodeifian, F. Razmimanesh, S. A. Sajadian, H. Soltani Panah, Solubility measurement of an antihistamine drug (Loratadine) in supercritical carbon dioxide: Assessment of qCPA and PCP-SAFT equations of state, Fluid Phase Equilib. 472 (2018) 147-159, doi: https://doi.org/10.1016/j.fluid.2018.05.018.

97. G. Sodeifian, S. A. Sajadian, R. Derakhsheshpour, Experimental measurement and thermodynamic modeling of Lansoprazole solubility in supercritical carbon dioxide: Application of SAFT-VR EoS, Fluid Phase Equilib. 507 (2020) 112422, doi: https://doi.org/10.1016/j.fluid.2019.112422.

98. G. Sodeifian, F. Razmimanesh, S. A. Sajadian, Prediction of solubility of sunitinib malate (an anti-cancer drug) in supercritical carbon dioxide $\left(\mathrm{SC}-\mathrm{CO}_{2}\right)$ : Experimental correlations and thermodynamic modeling, J. Mol. Liq. 297 (2020) 111740, doi: https://doi.org/10.1016/j.molliq.2019.111740.

99. G. Sodeifian, F. Razmimanesh, N. Saadati Ardestani, S. A. Sajadian, Experimental data and thermodynamic modeling of solubility of Azathioprine, as an immunosuppressive and anti-cancer drug, in supercritical carbon dioxide, J. Mol. Liq. 299 (2020), doi: https://doi.org/10.1016/j.molliq.2019.112179.

100. G. Sodeifian, F. Razmimanesh, S. A. Sajadian, S. M. Hazaveie, Experimental data and thermodynamic modeling of solubility of Sorafenib tosylate, as an anti-cancer drug, in supercritical carbon dioxide: Evaluation of Wong-Sandler mixing rule, J. Chem. Thermodyn. 142 (2020) 105998, doi: https://doi. org/10.1016/j.jct.2019.105998.

101. G. Sodeifian, S. M. Hazaveie, S. A. Sajadian, N. Saadati Ardestani, Determination of the Solubility of the Repaglinide Drug in Supercritical Carbon Dioxide: Experimental Data and Thermodynamic Modeling, J. Chem. Eng. Data (2019), doi: https://doi.org/10.1021/acs.jced.9b00550.

102. G. Sodeifian, S. M. Hazaveie, S. A. Sajadian, F. Razmimanesh, Experimental investigation and modeling of the solubility of oxcarbazepine (an anticonvulsant agent)in supercritical carbon dioxide, Fluid Phase Equilib. 493 (2019) 160-173, doi: https://doi.org/10.1016/j.fluid.2019.04.013.

103. G. Sodeifian, N. Saadati Ardestani, S. A. Sajadian, Solubility measurement of a pigment (Phthalocyanine green) in supercritical carbon dioxide: Experimental correlations and thermodynamic modeling, Fluid Phase Equilib. 494 (2019) 61-73, doi: https://doi.org/10.1016/j.fluid.2019.04.024.

104. M. Hamadache, O. Benkortbi, S. Hanini, A. Amrane, L. Khaouane, C. Si Moussa, A Quantitative Structure Activity Relationship for acute oral toxicity of pesticides on rats: Validation, domain of application and prediction, J. Hazard.
Mater. 303 (2016) 28-40, doi: https://doi.org/10.1016/j. jhazmat.2015.09.021.

105. V. H. Masand, V. Rastija, PyDescriptor: A new PyMOL plugin for calculating thousands of easily understandable molecular descriptors, Chemom. Intell. Lab. Syst. 169 (2017) 12-18, doi: https://doi.org/10.1016/j.chemolab.2017.08.003.

106. I. V Tetko, J. Gasteiger, R. Todeschini, A. Mauri, D. Livingstone, P. Ertl, V. A. Palyulin, E. V Radchenko, N. S. Zefirov, A. S. Makarenko, others, Virtual computational chemistry laboratory--design and description, J. Comput. Aided. Mol. Des. 19 (2005) 453-463, doi: https://doi.org/10.1007/s10822005-8694-y.

107. M. Hamadache, S. Hanini, O. Benkortbi, A. Amrane, L. Khaouane, C. S. Moussa, Artificial neural network-based equation to predict the toxicity of herbicides on rats, Chemom. Intell. Lab. Syst. 154 (2016) 7-15, doi: https://doi. org/10.1016/j.chemolab.2016.03.007.

108. A. H. Elsheikh, S. W. Sharshir, M. Abd Elaziz, A. E. Kabeel, W. Guilan, Z. Haiou, Modeling of solar energy systems using artificial neural network: A comprehensive review, Sol. Energy 180 (2019) 622-639, doi: https://doi.org/10.1016/j. solener.2019.01.037.

109. A. M. Ghaedi, A. Vafaei, Applications of artificial neural networks for adsorption removal of dyes from aqueous solution: A review, Adv. Colloid Interface Sci. 245 (2017) 20-39, doi: https://doi.org/10.1016/j.cis.2017.04.015.

110. J. Zupan, J. Gasteiger, Neural networks for chemists: an introduction (John Wiley \& Sons, Inc., 1993).

111. A. J. Smola, B. Schölkopf, A tutorial on support vector regression, Stat. Comput. 14 (2004) 199-222, doi: https://doi. org/10.1023/B:STCO.0000035301.49549.88.

112. V. Vapnik, Statistical Learning Theory/Vapnik V.--NY, (1998).

113. J. Chrastil, Solubility of solids and liquids in supercritical gases, J. Phys. Chem. 86 (1982) 3016-3021, doi: https://doi. org/10.1021/j100212a041.

114. J. Méndez-Santiago, A. S. Teja, The solubility of solids in supercritical fluids, Fluid Phase Equilib. 158-160 (1999) 501510, doi: https://doi.org/10.1016/s0378-3812(99)00154-5.

115. K. Keshmiri, A. Vatanara, Y. Yamini, Development and evaluation of a new semi-empirical model for correlation of drug solubility in supercritical $\mathrm{CO}_{2}$, Fluid Phase Equilib. 363 (2014) 18-26, doi: https://doi.org/10.1016/j.fluid.2013.11.013.

116.X.-Q. Bian, Q. Zhang, Z.-M. Du, J. Chen, J.-N. Jaubert, A five-parameter empirical model for correlating the solubility of solid compounds in supercritical carbon dioxide, Fluid Phase Equilib. 411 (2016) 74-80, doi: https://doi. org/10.1016/j.fluid.2015.12.017.

117. A. Baghban, A. Jalali, A. H. Mohammadi, S. Habibzadeh, Efficient modeling of drug solubility in supercritical carbon dioxide, J. Supercrit. Fluids 133 (2018) 466-478, doi: https:// doi.org/10.1016/j.supflu.2017.10.032.

118. G. Sodeifian, S. A. Sajadian, F. Razmimanesh, N. S. Ardestani, A comprehensive comparison among four different approaches for predicting the solubility of pharmaceutical solid compounds in supercritical carbon dioxide, Korean J. Chem. Eng. 35 (2018) 2097-2116, doi: https://doi.org/10.1007/ s11814-018-0125-6.

119. A. Aminian, Estimating the solubility of different solutes in supercritical $\mathrm{CO}_{2}$ covering a wide range of operating conditions by using neural network models, J. Supercrit. Fluids 125 (2017) 79-87, doi: https://doi.org/10.1016/j.supflu.2017.02.007.

120. M. R. Dadkhah, A. Tatar, A. Mohebbi, A. Barati-Harooni, A. Najafi-Marghmaleki, M. M. Ghiasi, A. H. Mohammadi, F. Pourfayaz, Prediction of solubility of solid compounds in supercritical $\mathrm{CO}_{2}$ using a connectionist smart technique, 
J. Supercrit. Fluids 120 (2017) 181-190, doi: https://doi. org/10.1016/j.supflu.2016.06.006.

121.X. Q. Bian, Q. Zhang, L. Zhang, J. Chen, A grey wolf optimizer-based support vector machine for the solubility of aromatic compounds in supercritical carbon dioxide, Chem. Eng. Res. Des. 123 (2017) 284-294, doi: https://doi. org/10.1016/j.cherd.2017.05.008.

122. B. Vaferi, M. Karimi, M. Azizi, H. Esmaeili, Comparison between the artificial neural network, SAFT and PRSV approach in obtaining the solubility of solid aromatic compounds in supercritical carbon dioxide, J. Supercrit. Fluids 77 (2013) 44-51, doi: https://doi.org/10.1016/j.supflu.2013.02.027.

123. A. Eslamimanesh, F. Gharagheizi, A. H. Mohammadi, D. Richon, Artificial Neural Network modeling of solubility of supercritical carbon dioxide in 24 commonly used ionic liquids, Chem. Eng. Sci. 66 (2011) 3039-3044, doi: https:// doi.org/10.1016/j.ces.2011.03.016.

124. H. Ahmadi, M. Rodehutscord, Application of Artificial Neural Network and Support Vector Machines in Predicting Metabolizable Energy in Compound Feeds for Pigs, Front. Nutr. 4 (2017) 1-8, doi: https://doi.org/10.3389/fnut.2017.00027.

125. S. Andrea, T. Stefano, C. Francesca, R. Marco, Sensitivity Analysis in Practice: A Guide to Assessing Scientific Models (John Wiley \& Sons, Ltd, 2004), doi: https://doi. org/10.1002/0470870958.

126. E. Uzlu, A. Akpinar, H. T. Özturk, S. Nacar, M. Kankal, Estimates of hydroelectric generation using neural networks with the artificial bee colony algorithm for Turkey, Energy 69 (2014) 638-647, doi: https://doi.org/10.1016/j.energy.2014.03.059.

127. S. A. Shojaee, H. Rajaei, A. Z. Hezave, M. Lashkarbolooki, F. Esmaeilzadeh, Experimental investigation and modeling of the solubility of carvedilol in supercritical carbon dioxide, J. Supercrit. Fluids 81 (2013) 42-47, doi: https://doi. org/10.1016/j.supflu.2013.04.013.
128. S. A. L. I. Shojaee, H. Rajaei, A. L. I. Z. Hezave, Experimental solubility measurement of cephalexin in supercritical carbon dioxide, Chem. Ind. Chem. Eng. Q. 20 (3) (2014) 387-396, doi: https://doi.org/10.2298/CICEQ121128021S

129. M. Lashkarbolooki, A. Z. Hezave, Y. Rahnama, R. Ozlati, H. Rajaei, F. Esmaeilzadeh, Solubility of cyproheptadine in supercritical carbon dioxide; experimental and modeling approaches, J. Supercrit. Fluids 84 (2013) 13-19, doi: https:// doi.org/10.1016/j.supflu.2013.09.004.

130. A. Zeinolabedini Hezave, H. Rajaei, M. Lashkarbolooki, F. Esmaeilzadeh, Analyzing the solubility of fluoxetine hydrochloride in supercritical carbon dioxide, J. Supercrit. Fluids 73 (2013) 57-62, doi: https://doi.org/10.1016/j.supflu.2012.11.005.

131. S. A. Shojaee, A. Z. Hezave, S. Aftab, M. Lashkarbolooki, F. Esmaeilzadeh, Solubility of gabapentin in supercritical carbon dioxide, J. Supercrit. Fluids 78 (2013) 1-6, doi: https:// doi.org/10.1016/j.supflu.2013.02.003.

132. H. Rajaei, A. Z. Hezave, M. Lashkarbolooki, F. Esmaeilzadeh, Representing experimental solubility of phenylephrine hydrochloride in supercritical carbon dioxide and modeling solute solubility using semi-empirical correlations, J. Supercrit. Fluids 75 (2013) 181-186, doi: https://doi. org/10.1016/j.supflu.2012.11.014.

133. S. A. Shojaee, H. Rajaei, A. Z. Hezave, M. Lashkarbolooki, F. Esmaeilzadeh, Experimental measurement and correlation for solubility of piroxicam (a non-steroidal anti-inflammatory drugs (NSAIDs)) in supercritical carbon dioxide, J. Supercrit. Fluids 80 (2013) 38-43, doi: https://doi.org/10.1016/j.supflu.2013.03.015.

134. A. Z. Hezave, S. Shahnazar, H. Rajaei, M. Lashkarbolooki, F. Esmaeilzadeh, Solubility of spironolactone in supercritical carbon dioxide: Experimental and modeling approaches, Fluid Phase Equilib. 355 (2013) 130-134, doi: https://doi. org/10.1016/j.fluid.2013.07.003.

\title{
SAŽETAK
}

\section{Primjena umjetne neuronske mreže i regresije potpornih vektora u modeliranju kvantitativnog odnosa strukture-svojstva i topljivosti otopljenih čvrstih tvari u superkritičnom $\mathrm{CO}_{2}$

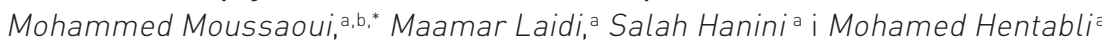

\begin{abstract}
U ovom je istraživanju korelirana topljivost 145 čvrstih otopljenih tvari u superkritičnom $\mathrm{CO}_{2}$ $\left(\mathrm{sCCO}_{2}\right)$ primjenom tehnika računalne inteligencije zasnovanim na modelima kvantitativne strukture i svojstva (QSPR). Baza podataka 3637 topljivosti prikupljena je iz prethodno objavljenih radova. Program Dragon primijenjen je za izračunavanje molekularnih deskriptora 145 čvrstih sustava. Genetski algoritam (GA) implementiran je kako bi se optimizirao podskup deskriptora sa značajnim doprinosom. Ukupno prosječno apsolutno relativno odstupanje MAARD od oko $1,345 \%$ između eksperimentalnih i izračunatih vrijednosti pomoću regresije potpornih vektora modelom SVR-QSPR dobiveno je za predviđanje topljivosti 145 čvrstih otopljenih tvari u superkritičnom $\mathrm{CO}_{2}$, što je bolje od onog dobivenog primjenom modela ANN-QSPR (2,772\%). Rezultati pokazuju da je razvijeni model SVR-QSPR precizniji i da se može primijeniti kao alternativni alat za modeliranje QSAR studija topljivosti otopljenih čvrstih tvari u superkritičnom ugljikovu dioksi$\mathrm{du}\left(\mathrm{scCO}_{2}\right)$. Točnost predloženog modela procijenjena je statističkom analizom uspoređivanjem rezultata s ostalim modelima zabilježenim u literaturi.
\end{abstract}

\section{Ključne riječi \\ Topljivost, otopljene čvrste tvari, superkritične tekućine, tehnike računalne inteligencije, kvantitativni odnos struktura-svojstvo}

${ }^{a}$ Laboratory of Biomaterials and Transport

Phenomena (LBMPT), University of Médéa,

Médéa, Alžir

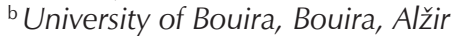

Izvorni znanstveni rad

Prispjelo 18. siječnja 2020. Prihvaćeno 13. svibnja 2020. 